\title{
U-stage and EBSD technique as complementary methods
}

\section{Cristiane Paula de Castro Gonçalves ${ }^{1}$ \& Leonardo Evangelista Lagoeiro ${ }^{1}$}

\begin{abstract}
In the last years, the electronic microscopy has become an important tool to textural analyses of mineral aggregates. The electron backscattering diffraction (EBSD) has been used to determine preferred orientation patterns quickly in areas statistically representative. However, when the grain boundary geometry and their orientations are considered, there is not a way to determine the grain boundary orientation individually for EBSD, what is possible using U-stage mounted on a petrographic microscope. The geometry and grain boundary orientation pattern constitute important microstructural and textural parameters. They are directly related to deformational processes occurred during evolution and stabilization of mineral aggregates, as well as their physical properties. Therefore, when the microfabric is characterized is necessary, besides a complete characterization of crystallographic preferred orientation, to have individual control of geometry and grain boundary segments orientation. In this sense, the use of U-stage, although there are restrictions, is fundamental. This method allows the determination of grain boundary plane orientation, individually, while the EBSD permit a global analyze related to misorientation studies between those grains that share a boundary plane. Therefore, the methodology to characterization of grain boundary orientation patterns is presented. The referred methods are applied as complementary techniques, what allows the characterization of 5 degrees of freedom necessary to determine a boundary surface: the grain boundary plane orientation and the distribution of angle/axes misorientation pair. The data were obtained in quartz aggregates, which came from banded iron formation, in Quadrilátero Ferrífero (MG).
\end{abstract}

Keywords: texture, microstructures, grain boundary geometry, sample preparation for EBSD, U-stage.

\begin{abstract}
Resumo Platina Universal e técnica de elétrons retroespalhados difratados como métodos complementares. Nos últimos anos, o uso de microscopia eletrônica para análise textural de agregados minerais, por difração de elétrons retroespalhados (EBSD), tem se tornado importante meio para se determinar padrões de orientações preferenciais de maneira rápida e estatisticamente representativa. Entretanto, ao se considerar a geometria de borda dos grãos, não há como determinar a orientação das superfícies de borda, individualmente, por EBSD, o que se pode fazer através de platina universal acoplada a um microscópio ótico. A geometria e padrão de orientação das bordas dos grãos constituem importantes parâmetros microestrutural e textural que estão diretamente relacionados aos processos deformacionais ocorridos durante evolução e estabilização de determinado agregado, bem como às suas propriedades físicas. Portanto, ao se caracterizar a microtrama de um agregado é necessário que além de uma completa determinação das orientações cristalográficas preferenciais, se tenha controle da geometria e orientação dos segmentos de borda que limitam os grãos. Para tal, o uso da platina universal, apesar das restrições, é fundamental, já que permite a determinação das orientações das superfícies de borda individualmente, enquanto por EBSD tem-se uma análise global da relação de desorientação entre os grãos que compartilham uma borda. Nesse contexto, apresenta-se a metodologia para caracterização de padrões de orientação de bordas, aplicando os referidos métodos como técnicas complementares, o que permite a caracterização dos 5 graus de liberdade necessários: orientação do plano de borda, distribuição e orientação do par eixo-ângulo de desorientação. Para tal foram utilizados agregados de quartzo provenientes de formações ferríferas bandadas do Quadrilátero Ferrífero (MG).
\end{abstract}

Palavras-chave: textura, microestruturas, geometria de borda, preparação de amostras para EBSD, platina universal.

INTRODUCTION The microstructural and crystallographic orientation patterns of minerals in rocks are directly related to the physical, chemical and environmental conditions in which these aggregates were formed or deformed. This means that for a complete understanding of the mechanical behavior of a rock during deformation, a careful characterization of micro- structures, crystallographic preferred orientation (CPO) and shape preferred orientation (SPO) must be carried out in the aggregates. On the other hand, the characterization of microstructures must also take into account grain boundary properties, such as their spatial array and crystallographic orientation, since, in some cases, the boundaries may play an important role on the ac- 
commodation of the deformation. However, the study of grain boundary properties became an important matter in earth sciences only in the last decades, when grain boundary geometry in polycrystalline aggregates began to receive more attention.

Although at that time, grain boundary geometries, their relationship with the equilibrium of surface energy and their role in different geological situations remained poorly understood, there was a general agreement that their geometry might be used to determine physical and chemical properties of the aggregates as well as to infer metamorphic conditions (Randle 1992, Lloyd et al. 1997, Wheeler et al. 2001, Wheeler et al. 2003, Lloyd 2004). The poor knowledge about grain boundary arrangements is due, mainly, to difficulties to use optical methods to measure them, and for the difficulties to determine all parameters required for a complete boundary characterization. However, a complete investigation of how minerals behave under deformation demands a detailed analysis of such properties, as pointed out by many authors (Lloyd \& Freeman 1991, Randle 1992, Mainprice et al. 1993, Lloyd et al. 1997, Randle \& Engler 2000, Lloyd 2004).

The grain boundaries are characterized by two parameters with five degrees of freedom (Spry 1983, Randle 1992): (i) the orientation of the boundary plane (parameter with two degrees of freedom, the plane azimuth and its dip); (ii) the misorientation between two neighbor grains, which share the same boundary. In rocks and minerals in general (except isometric ones), these crystallographic information of grain boundaries can be obtained using serial sections and stereology (Randle 1992) or in a easier manner using only one section and applying U-stage and EBSD techniques as complementary methods (Kuntcheva et al. 2006). The U-Stage is mounted on a petrographic microscope, through which is possible to determine the boundary plane orientation, while the analysis of the misorientation axis/angle pair is made via Electron Backscattering Diffraction - EBSD technique (Randle 1992, Dingley et al. 1995, Prior et al. 1999, Humphreys 2001, Prior et al. 2002). Both methods are useful in different aspects on determination of grain boundary properties, and therefore, should be used as complementary techniques, in order to obtain a more complete analysis of such characteristics (Kuntcheva et al. 2006).

In this sense, the grain boundary microstructures, their geometry and orientation patterns were carried out in quartz aggregates from tectonites of banded iron formation, which came from Quadrilátero Ferrífero (MG). As the quartz grains register even the lowest deformation levels, they are considered deformation markers, furthermore, the preferred orientation patterns for quartz grains associated to different deformational and metamorphic conditions are well knew and largely discussed in the literature (e.g. Tullis et al. 1973, Schmid \& Casey 1986, Law et al. 1990, Law 1990, Hirth \& Tullis 1992, Kruhl 1996, Lloyd et al. 1997, Lagoeiro 1998, Hippertt et al. 2001, Stipp et al. 2002, Heilbronner \& Tullis 2002). Therefore, the study of quartz ag- gregates found in itabirites in the region of Quadrilátero Ferrífero constitute an important way to understand the deformational mechanisms through which the features and structures observed in these rocks were generated. Besides, the banded iron formations in the Quadrilátero Ferrífero (MG) are distributed around a large area and they register the most important deformational and metamorphic events occurred during the geological time in this region (Alkmim \& Marshak 1998). In addition, the researchers have shown a metamorphic and deformational gradient from western to east portion of the area (Pires 1995, Rosière 2001) and, therefore, as the grain boundary geometry and their orientation patterns to mineral aggregates remain poorly understood the referred samples should be used to characterize the grain boundary arrangement in different tectonometamorphic context.

For those reasons, the aim of this contribution is presenting the methodology used to characterize the grain boundary geometry and grain boundary orientation patterns, once there is not, in the literature, the description of the procedures used. The U-stage and EBSD system are presented as complementary techniques, being that the limitation and complementary of these two techniques are discussed in order to accomplish a detailed characterization of the grain boundary array in recrystallized quartz grains. The data obtained, showing misorientation and grain boundary orientation patterns from samples in different metamorphic contexts, illustrate the kinds of graphs and diagrams plotted and how they should be interpreted.

\section{METHODS}

Sample Preparation The first step is a careful procedure to sample preparation. Then, the samples were selected according to some specific features. In all samples quartz bands are continuous (in range of several centimeters) and thick (between $2-10 \mathrm{~mm}$ ). The $\mathrm{X}, \mathrm{Y}$ and $\mathrm{Z}$ reference system used in structural geology, corresponding to the main axis of the finite strain ellipsoid (Twiss \& Moores 1992, Passchier \& Trouw 1996), where X axis is parallel to the mineral elongation, $\mathrm{Z}$ axis normal to the foliation and Y-axis perpendicular to the XZ plane, was

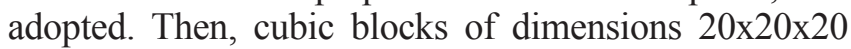
$\mathrm{mm}$ were prepared for polishing (Fig. 1).

All samples were cut parallel to the stretching lineation (strain-X) and perpendicularly to the rock foliation (XZ plane) using a low-speed saw to prevent damaged on sample surfaces. Sections for EBSD and optical analyses were prepared in a closely match to minimize the misfit of the observed areas (Fig. 2): (i) blocks of $15 \times 15 \times 7 \mathrm{~mm}$ were obtained and enclosed into an epoxy resin for EBSD analysis (Fig. 2a); (ii) regular thin sections $(\approx 0,03 \mathrm{~mm}-$ Fig. 2 b) were prepared as well as (iii) thick sections $(\approx 0,07 \mathrm{~mm})$, for U-stage measurements of grain boundary plane orientation (Fig. 2c).

The normal thin sections were used for microstructural observations and to select potential areas for EBSD and U-stage analyses. We selected aggregates of quartz grains free of iron oxide inclusions, to avoid the 

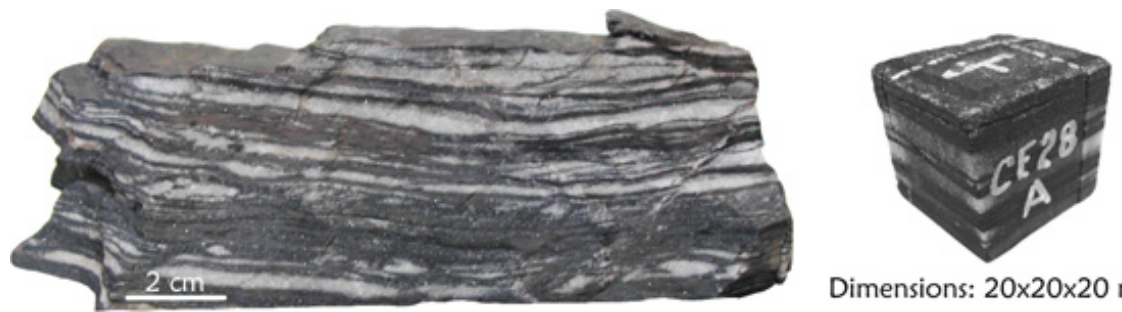

Dimensions: $20 \times 20 \times 20 \mathrm{~mm}$

Figure 1 - Sample of banded iron formation in which thicker quartz bands can be observed and a block from which the sections were prepared.

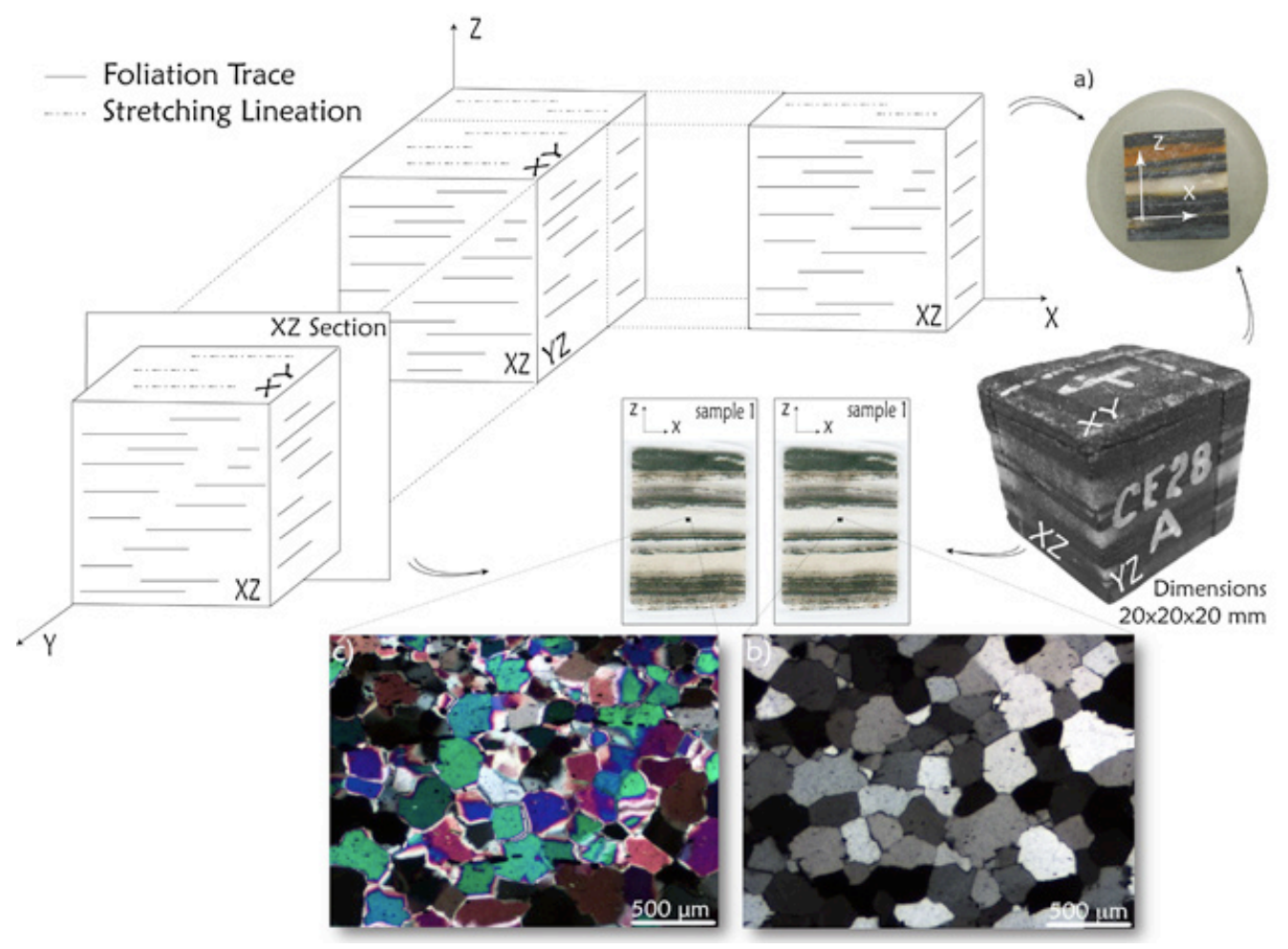

Figure 2 - Schematic figure illustrating the tree kinds of prepared samples. Blocks with $20 \times 20 \times 20 \mathrm{~mm}$ blocks with $15 \times 15 \times 7 \mathrm{~mm}$ were cut and closed in epoxy resin (a); thin sections with 'normal' thickness, $\approx 0,03 \mathrm{~mm}$, were made (b), as well as thicker sections, $\approx 0,07 \mathrm{~mm}(\mathrm{c})$.

interference of these mineral phases during the recrystallization processes. Therefore quartz bands can be considered pure and free of iron oxide minerals. Then, the blocks were enclosed in epoxy resin for EBSD analysis while the thick sections were used to measure the crystallographic orientations of grain boundaries, in the U-stage.

Sample preparation is crucial for EBSD analysis. The analyzed sample surface must be perfectly flat and free of any type of mechanical damage resulting from the polishing. To accomplish that, the MINIMET 1000 - Grinder Polisher was used. Initially, the samples were enclosed in epoxy resin and their sharp edge was removed using sandpaper (Fig. 3). This procedure is necessary to enhance the polishing process once it allows that the whole sample surface is in contact with the grinder fluid paste.

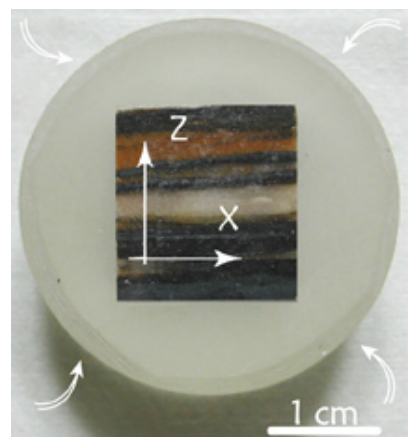

Figure 3 - Sample closed in epoxy resin whose boundaries are smoothed, in order to facilitate its slide on the polishing discs. 
Initially, all excess of resin is removed from the sample surface what involves a mechanical polishing with a diamond disc of grain size of $45 \mu \mathrm{m}$, an applied force of 2 or $3 \mathrm{lb}$, and rotation of $30 \mathrm{rpm}$. The sample and polisher disc should be immersed in distilled water. The time required for polishing varies, and depends on the material properties. Geological samples must be polished at least for 30 seconds or until the resin that covers the sample surface is completely removed (Fig. 4a). In this case, time consumption varies from 15 minutes up to 2 hours, depending on the thickness of the quartz band, as well as the proportion between quartz grains and iron oxides.

The next step is to polish the sample surface with a diamond disc of smaller grain size, $15 \mu \mathrm{m}$ in this case, whose aim is to soften the defects generated on the surface of the sample during the previous stage. This disc should be used while amounts of resin can be identified on the sample surface, but care should be taken with the time, since it should not exceed ten minutes (Fig. $4 \mathrm{a}-\mathrm{b}$ ). The discs of grain size of 45 and $15 \mu \mathrm{m}$ can be substituted for silicon carbide-paper discs, a synthetic abrasive material. However, there are some disadvan- tages in the use of silicon carbide: as the sample needs to be immersed in distilled water during the polishing, the durability of paper disc is lower and the time required to this first polishing stage is larger.

In the third step, the mechanical polishing should be done with diamond past in oil medium (AUTOMET Lapping Oil). The process started with diamond past of $9 \mu \mathrm{m}$ in a Nylon polisher cloth (Fig. 5a). A load of $5 \mathrm{lb}$ was applied at $30 \mathrm{rpm}$. The running time was, in average, 45 minutes and it is recommendable does not exceed one hour. In average, about 45 minutes was spent for each size of diamond paste used: $9 \mu \mathrm{m}, 3 \mu \mathrm{m}, 1 \mu \mathrm{m}$ and $0.25 \mu \mathrm{m}$, being that for the two last pastes a softer polisher clothe was used, a load of $31 \mathrm{~b}$ was applied at $30 \mathrm{rpm}$ (Fig. 5b). Between each size intervals of diamond paste, the samples were ultrasonically cleaned, with distilled water, to eliminate any residue of the preceding paste. A visual inspection of the surface quality of the sample must be done in an optical incident light microscope.

In the final stage a mechanical and chemical polishing must be accomplished to make sure that all imperfection and mechanical deformation induced dur- a)
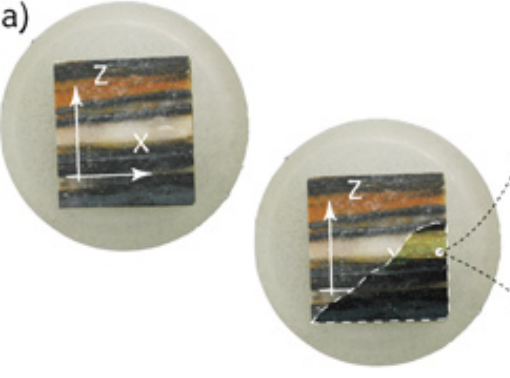
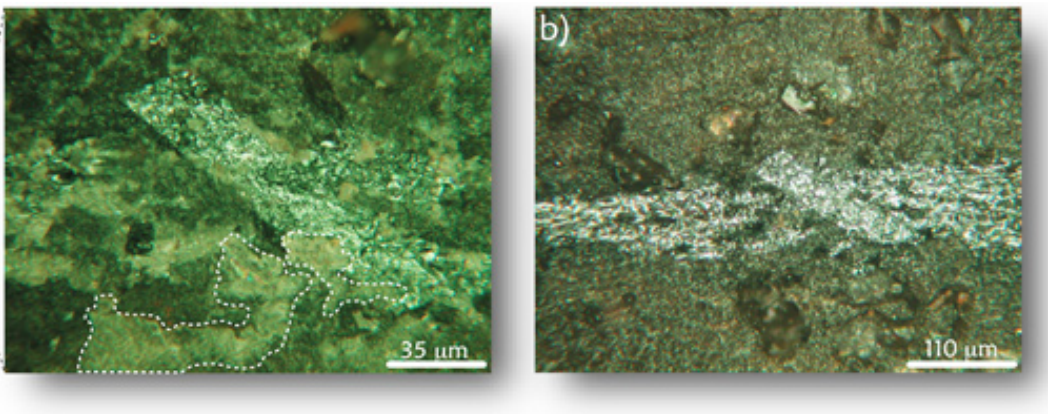

Figure 4 - The illustration represents the first polishing stage; a) in the left side, sample enclosed in epoxy resin without polishing, followed for a partially polished sample, in which an area, apparently, without epoxy resin is selected. However, the micrograph shows some stains (two are contoured) on the sample, which represents rests of epoxy resin. These stains should be removed by disc with $15 \mu \mathrm{m}$ so that the sample does not be too deformed, superficially; b) Photomicrograph showing the sample without resin, after the use of the disc with $15 \mu \mathrm{m}$.
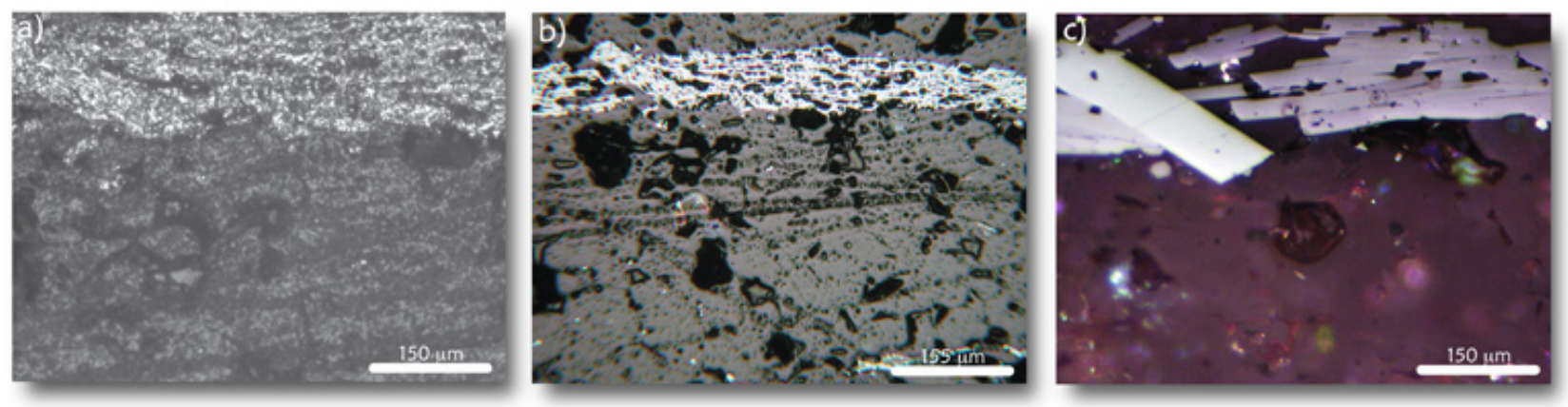

Figure 5 - Photomicrographs showing the same region of the sample in different polishing stages. The light gray represents hematite grains while the dark gray represents quartz grains; a) after polishing with $9 \mu \mathrm{m}$ diamond paste; b) after polishing with $0.25 \mu \mathrm{m}$ diamond paste; $c$ ) in the end of the polishing procedure, when colloidal silica solution was utilized. 
ing cutting is eliminated. The polishing must be made with an alkaline solution of colloidal silica, SYTON (Fynn \& Powell 1979), of grain size of $20 \mathrm{~nm}$. A soft polisher cloth must be used and the surface of the sample must be completely immersed in the solution, at a speed as lower as $30 \mathrm{rpm}$ and with a minimum applied load $(\sim 1 \mathrm{lb})$. The lapping time required is around 8-10 hours, in average, for the studied samples (Fig. 5c).

For non-conductive samples, it is necessary to cover the sample surface with a very thin layer of carbon of few nanometers of thickness. However, extra care is necessary because even a nanometric cover of carbon might interfere with the generation of the diffraction pattern, kikuchi bands (Prior et al. 1999). In this case, initially, the sample must be cleaned with acetone, after ultrasonically cleaned with distilled water, at least for 25 minutes, and the last polishing stage with colloidal silica must be repeated for about 4 hours (Fig. 6).
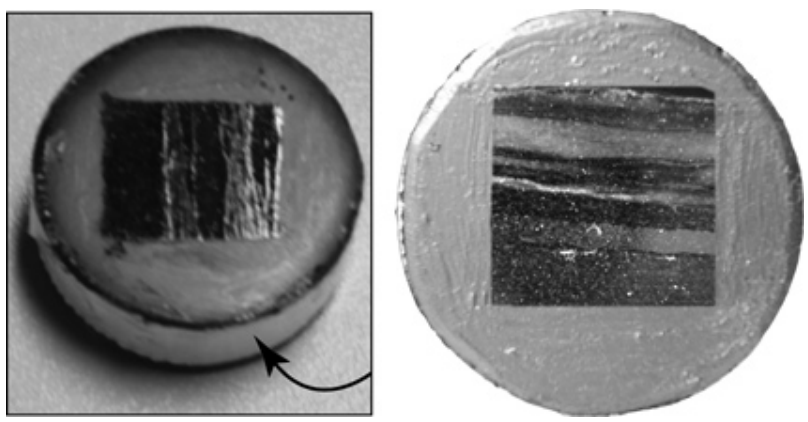

Figure 6 - Ready samples for the EBSD analyses. As it is recommended that the samples should not be covered by carbon, they are surrounded by metallic tape (a) and in the surface of the sample the section is bordered by carbon paint (b), so the electrons are not concentrated on the sample.
Data Acquisition Initially, suitable quartz bands were selected for U-stage measurements. A mosaic of optical micrograph was composed and grain boundaries were mapped out manually. In the grain boundary map, grains were indexed for boundary orientation measurement and for determination of grain size distribution (Fig. 7).

In the thick sections, boundaries inclined to the section plane are visualized as diffuse strips. Shallow grain boundaries appear as broad diffuse bands (Fig. $8 \mathrm{a})$. As the U-stage allows the rotation of inclined boundaries to the vertical position, the attitude of grain boundary plane can be measured with precision of $1^{\circ}$ (Fig. 8b). These data combined with the EBSD results will permit the complete characterization of grain boundary geometry.

Universal Stage The technique was first applied, on the study of grain boundaries, by Kruhl \& Peternell (2002) and later by Kuntcheva et al. (2006) and it allows the determination of the three-dimensional orientation of grain boundary planes on the micrometer-scale with acceptable accuracy. The procedure is rotating the section according to the U-stage axes until those segments which appear as diffuse bands become straight lines. The segments are visualized as diffuse bands because the grain boundary plane is tilted. When the section is rotated, the grain boundary plane becomes normal to the section plane and then the boundary segment appears as a sharp line. In this position, its orientation is represented by the angle that the tilted position makes with the microscopy stage (horizontal position).

In figure 9 the procedure to obtain the grain boundaries orientations is illustrated. The first step is to select a pair of grains and measure the c-axis orientation of both. After that, the grain boundary shared by the two neighbor grains is divided in straight segments (or bands); select one of these segments and rotate it around a vertical axis of U-stage until the segment ap-

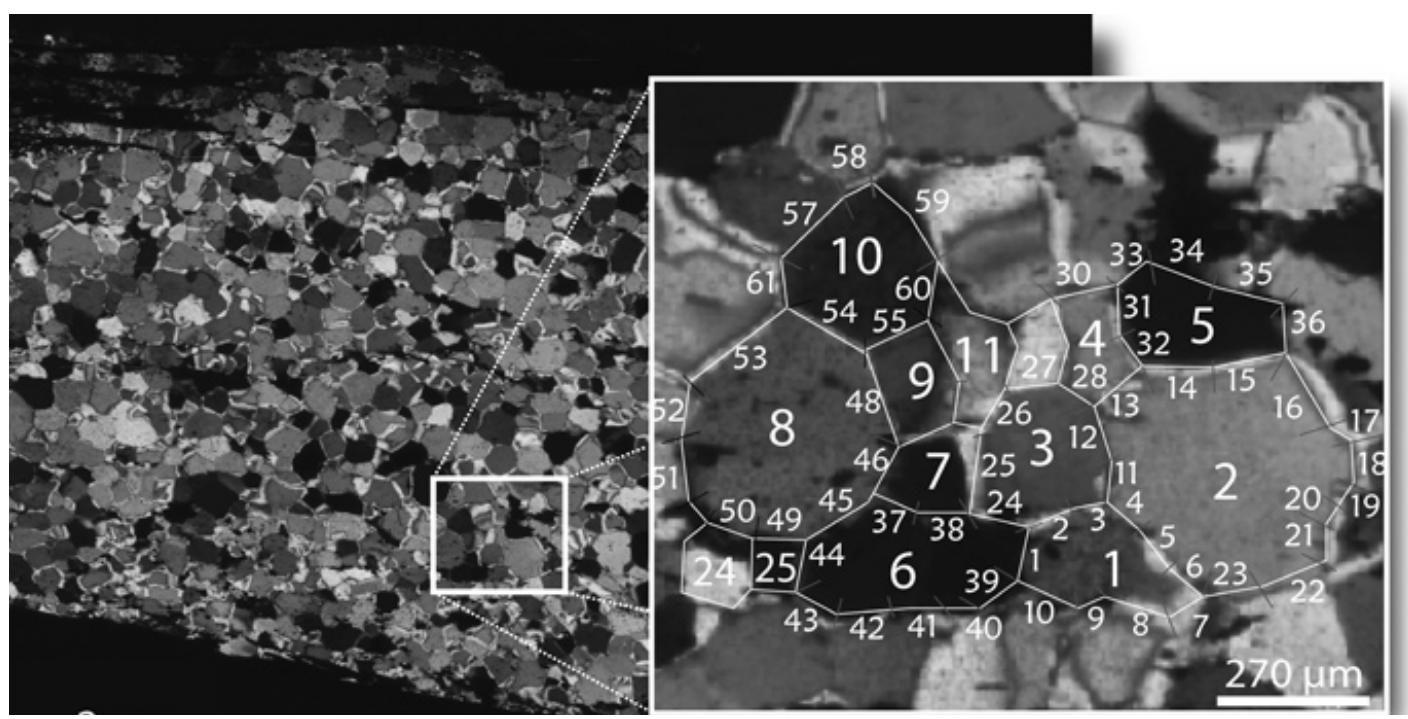

Figure 7 - Mosaic of quartz band, from which the region to be analyzed was selected. In detail, one region showing some indexed grains, as well as their boundaries. 

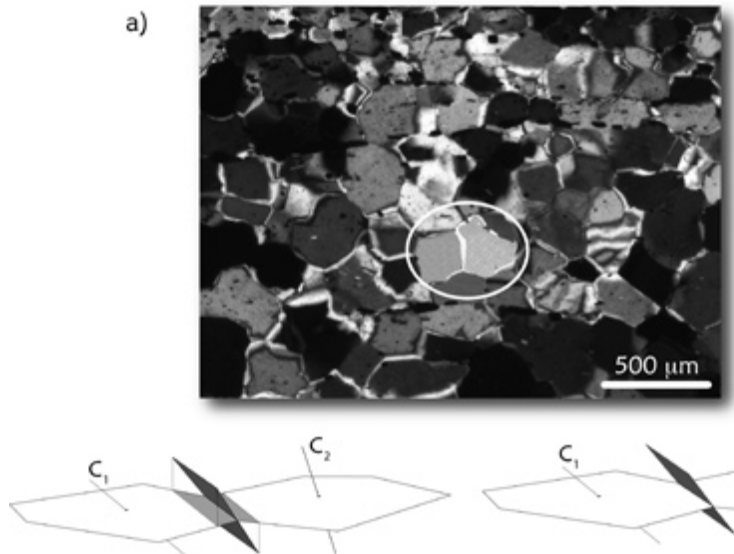

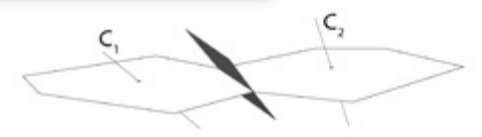

b)

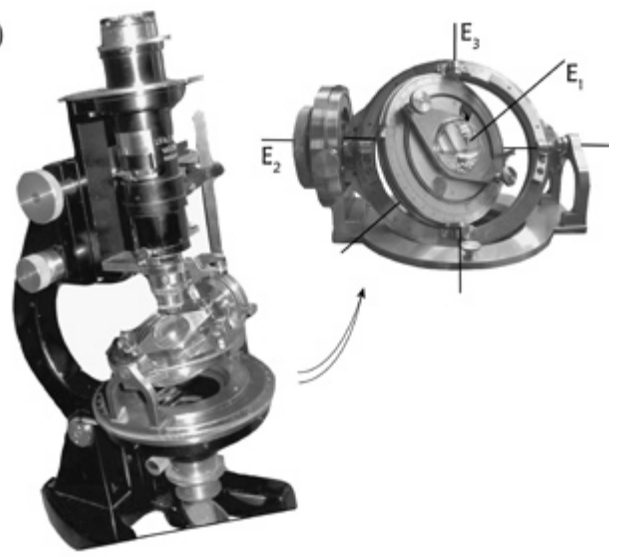

Figure 8 - a) Photomicrograph showing a region of a thicker section, in which two grains are circled and schematic illustrations of the relation between the grain boundary plane and the horizontal plane (section plane), reason due to which the boundary grain appears as diffuse bands; b) the U-stage coupled to the optical microscope, through which the grain boundary attitude can be determined.

a)
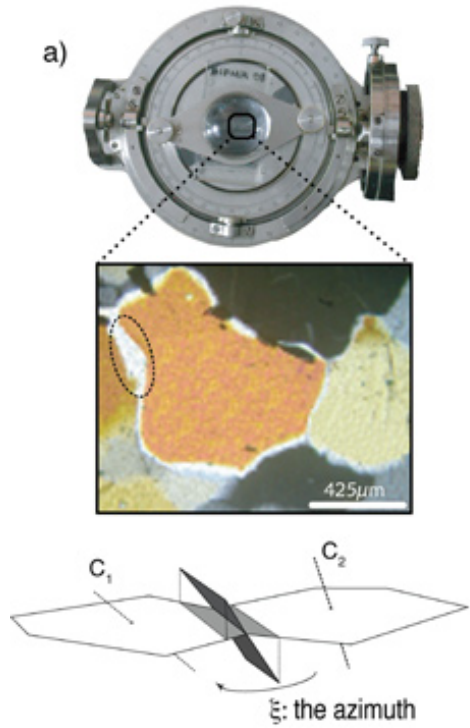

d)

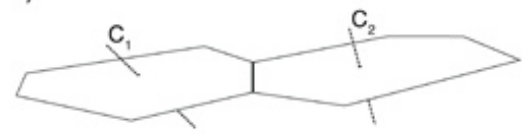

b)
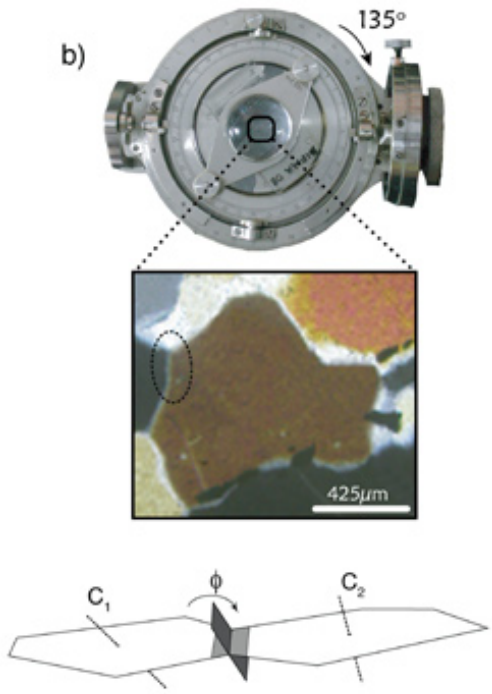

c)
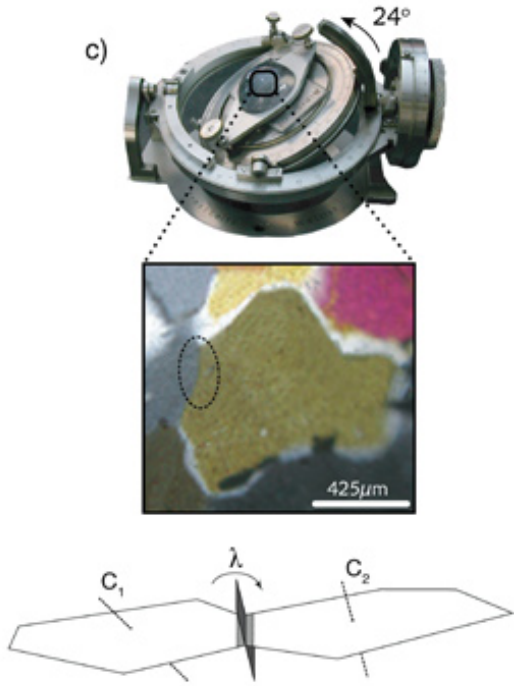

e)

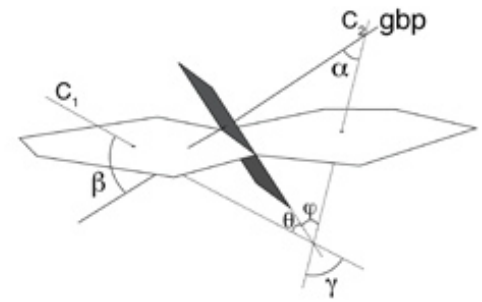

Figure 9 - Photomicrographs and schematic illustrations of the procedure to obtain the grain boundary plane attitude; a) the grain boundary must be rotated until to be parallel to the vertical reticulum of the U-stage, $135^{\circ}$ in the picture; $b$ and c) the boundary is rotated according to horizontal axis of the u-stage, until to be orthogonal to the section plane, and then, visualized as straight lines (dgrain boundary pole attitude determined: 315/66); e) through of described routine, considering two neighbor grains, c-axes and the grain boundary pole attitude can be measured $\left(C_{1}\right.$, $C_{2}$ and $\left.g b p\right)$; thus, the angular relations obtained are: the angles between the c-axes $(\gamma=\theta+\varphi)$; the angle between grain boundary pole and the c-axes ( $\alpha$ and $\beta$ ).

pears parallel to the vertical line of the cross hair (Fig. 9a). Thus, we determine the azimuth of the plane, which contains the segment. To determine its dip, the section is rotated according to one of the horizontal axes of $\mathrm{U}$ stage (Fig. 9 b-d). This method provides: (i) the orientation of grain boundary pole; (ii) the angles between 
the c-axes of neighbor grains; (iii) the angle between grain boundary pole and the c-axes, and then, the angle between the plane that contains the grain boundary segment and the c-axes (Fig. 9e). Based on the angle between the c-axes of neighbor grains and the grain boundary pole it is possible to determine the crystallographic orientation of the grain interface with respect to each of the neighboring grains and as all measured parameters are indexed (Fig. 7), it is possible to establish a safe correlation among the microstructures and texture of the aggregate.

RESTRICTIONOF THE METHOD Although through the optical method the spatial orientation of straight grain boundary segments can be measured, some restrictions of measurements should be considered. As the u-stage tilting is restricted to, approximately, $45^{\circ}$, segments of planes dipping between $0-45^{\circ}$ cannot be taken into the vertical position. Thus these segments cannot be measured with sufficient accuracy. On the other hand, if the grain boundaries are very irregular (lobated or serrated), the length of the grain boundary segment is too small, few micrometers, what can cause the interference between adjacent boundaries, mainly if these boundaries have low tilting angles. As these boundaries will be observed as diffuse belts, the limits of these belts cannot be determined precisely.

Electron Backscattering Diffraction The determination of grain boundary orientation characterizes two of the five degrees of freedom necessary to characterize the grain boundary geometry. The other three are described for the angle/axis misorientation pair, between two neighbor grains, which share the same boundary. The misorientation axis is the axis according to which one lattice must be rotated so that it becomes coincident with the neighbor lattice, while the misorientation angle is the angular difference between their spatial orientations. To obtain these parameters we have used a Scanning Electron Microscope (JEOL 5510) equipped with an Electron Backscattering Diffraction system (HKL Technology), with the CHANNEL $5^{\circ}$ application package. The measurements of the crystallographic orientations were made on a predefined surface of, approximately, $15 \mathrm{~mm}^{2}$, at a magnification of $25 \mathrm{X}$.

Initially, the sample must be carefully positioned. It must be in front of the EBSD detector with an inclination of $70^{\circ}$ (Prior et al. 1999, Humphreys 2001) and the three reference systems (sample reference system, specimen reference system and microscope reference system) must be coincident or their angular relations must be known (Fig. 10).

The EBSD technique allows a complete crystallographic orientation at the point struck by the electron beam in the form of Euler angles. Initially, in each point, the data are resolved in a form of diffraction pattern, known as Kikuchi Diffraction Pattern (Randle 1992 - Fig. 10). These diffraction patterns result from the interaction between the electron beam and the atomic planes of the crystal lattice. In a general way, the electrons interact with all crystallographic planes in each point hit by the beam, and backscattered electrons are diffracted and detected by the phosphor detector. Then, the results are processed and represented in a form of Kikuchi bands, which are analyzed, indexed and processed by computational applications (Prior et al. 1999). So that the diffraction pattern can be indexed correctly, the equipment must be carefully calibrated. The distance between the sample and the point in which the electron beam is liberated, the work distance, must be carefully determined to assure the correct indexation. In this case we used a work distance of $35 \mathrm{~mm}$ and a specific calibration was generated to this value.

The diffraction patterns acquired are compared
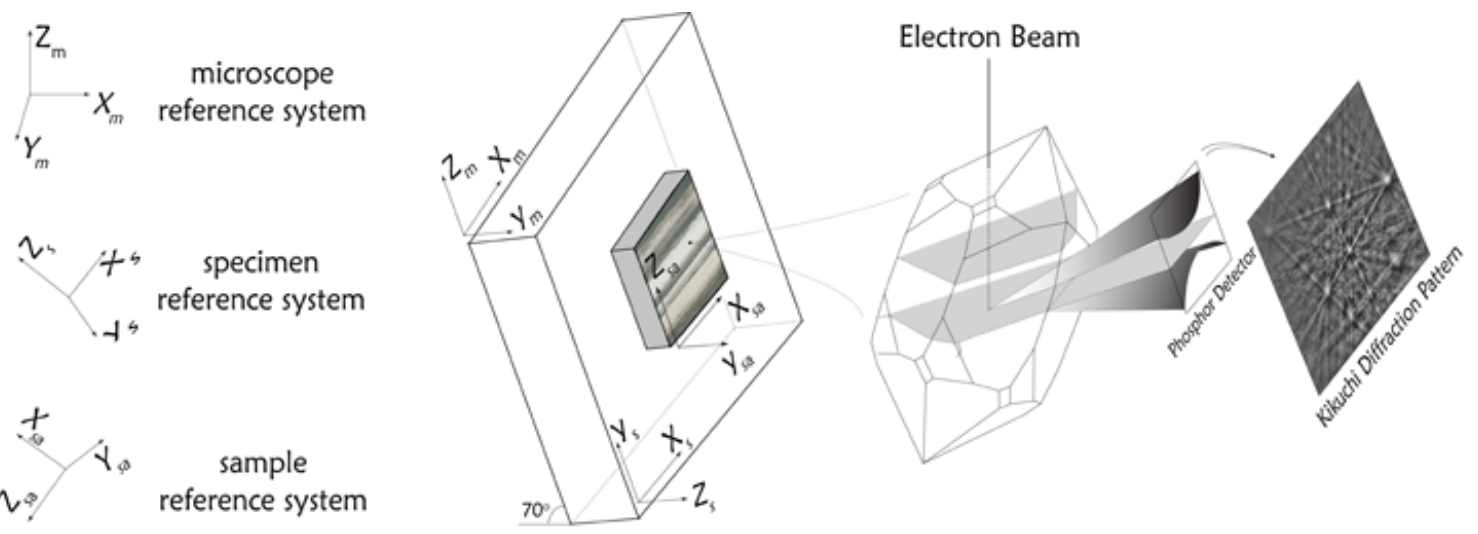

Figure 10 - Schematic illustration showing the sample positioned in the SEM camera. The sample must be tilted at $70^{\circ}$ the reference system of the microscope and the specimen (EBSD) and the sample reference system must be also coincident (to sample reference system, Zsa-foliation pole (Z) and Xsa-stretching lineation $(X)-X Z$ plane). In the right side, a schematic example of the diffraction pattern obtained when the electron beam strikes a quartz crystal and the diffraction pattern of backscattered electrons are projected to the phosphor detector. 
to a computer dataset allowing the determination of the crystallographic directions of crystal struck by the electron beam. The crystallographic orientation is determined according to the sample reference system (coincident with specimen and microscope reference systems, in this case, Fig. 10). Therefore three angles are necessary to characterize crystal orientation in the space, which are known as the Euler angles (Randle 1992). Hence, the crystallographic orientation is represented as a set of Euler angles, that correspond to specific rotations which became possible to transform sample coordinate system into the crystal coordinate system and vice versa (Bunge 1982). The points are indexed consecutively and the step size depends on the grain size, in this case the step size adopted was $10 \mu \mathrm{m}$ (Fig. 11).

The mathematical treatment of these data allows the determination of misorientation properties, to neighbor or random grains. The data can be presented in a form of orientation contrast image, pole figures or inverse pole figures, in which orientation distribution patterns of all crystallographic forms can be analyzed. In the first case, the data is presented as an orientation map with different colors to each pixel, depending on the crystallographic orientation of each indexed point. In the second situation, the crystallographic orientations are analyzed through diagrams in which they are plot- ted according to sample reference system, as pole figures diagram. In the last condition, the data are plotted according to the crystal reference system, i.e. as inverse pole figures. In this case, it is necessary to fix any external structure or an axis of the sample reference system, and then this parameter will be plotted according to the main crystallographic directions of the analyzed crystal. Lineation (X direction), foliation pole ( $\mathrm{Z}$ direction), grain boundary poles or any linear structure can be plotted and presented as inverse pole figures. The figure 12 shows the representation of the main crystallographic forms of a quartz crystal.

Due to quartz symmetry, the crystallographic forms are repeated in six sectors, but only that which appears in the right side of the figure is used in the inverse pole figures. The table 1 shows crystallographic forms plotted in the figure 12, as well as, their MillerBravais indices and the angle between their poles and c-axis.

The interpolation between orientation data for consecutively indexed points allows the determination of grain boundaries and grain boundary maps can be generated with an angular accuracy of $1^{\circ}$ or less. Then, the degree of misorientation between those regions individualized as grains, neighbor or randomly, can be used to infer the grain boundaries
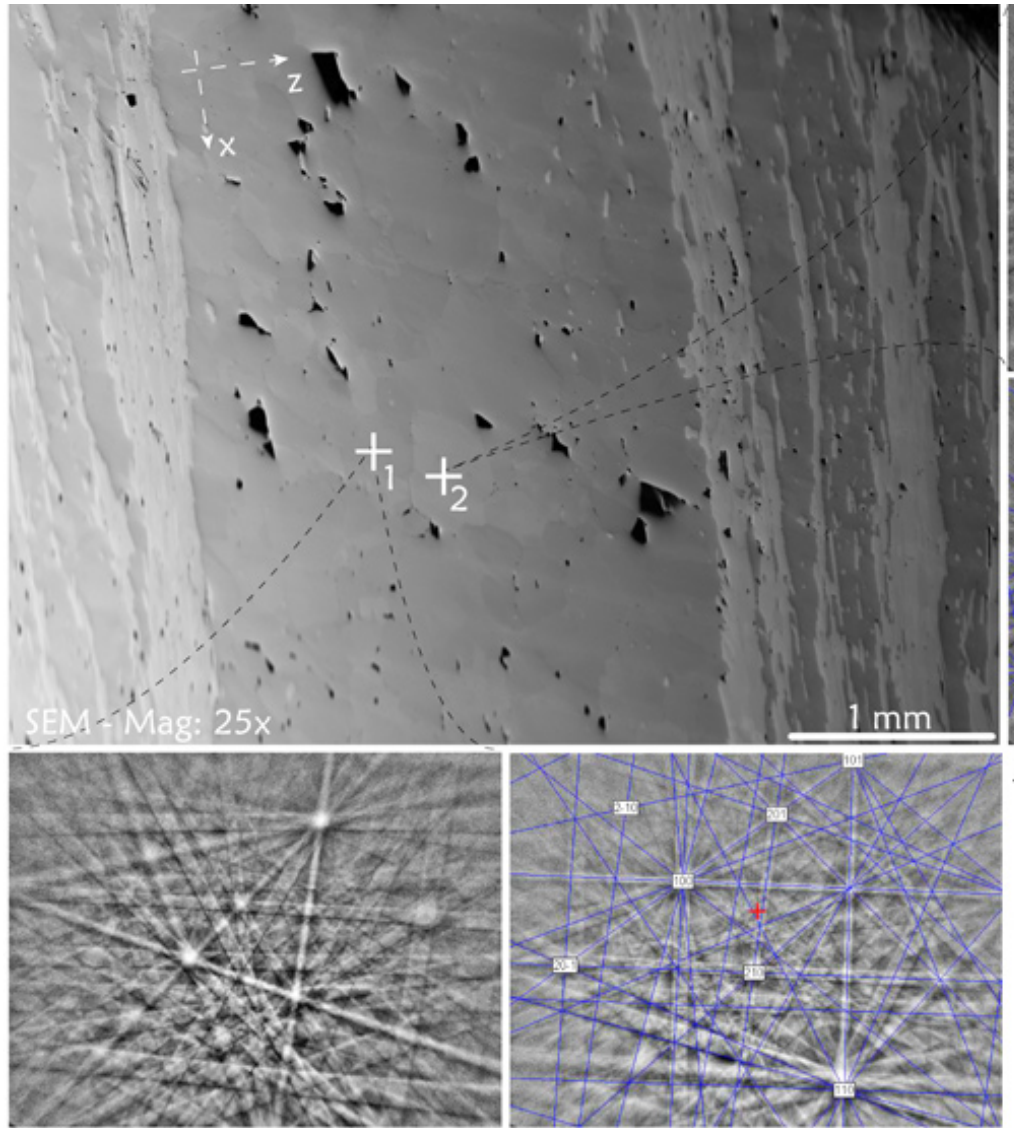

Kikuchi Diffraction Pattern

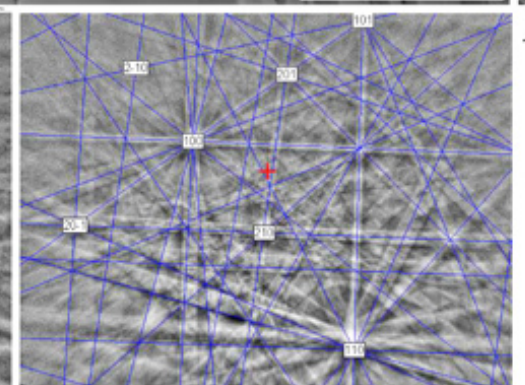

Indexed Diffraction Pattern

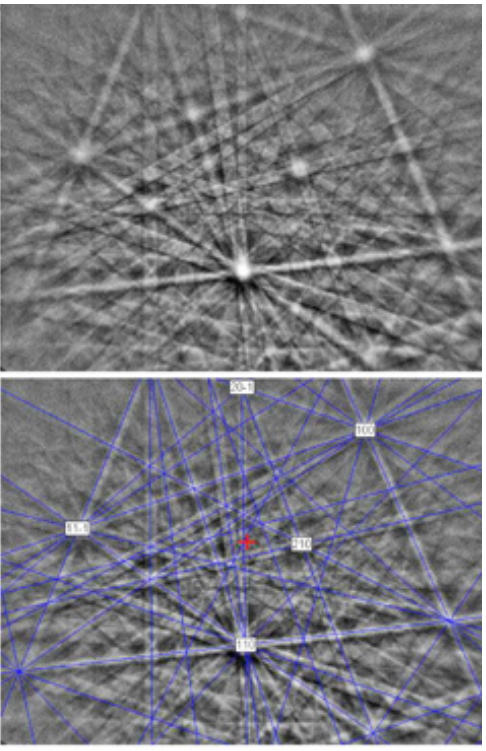

z

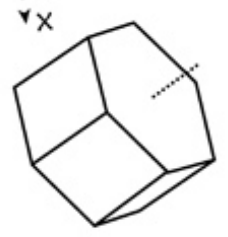

1

Figure 11 - Illustration of the detected and indexed diffraction pattern in two points, as well as, the determined position of the unit cell and its relation to the sample reference system. 


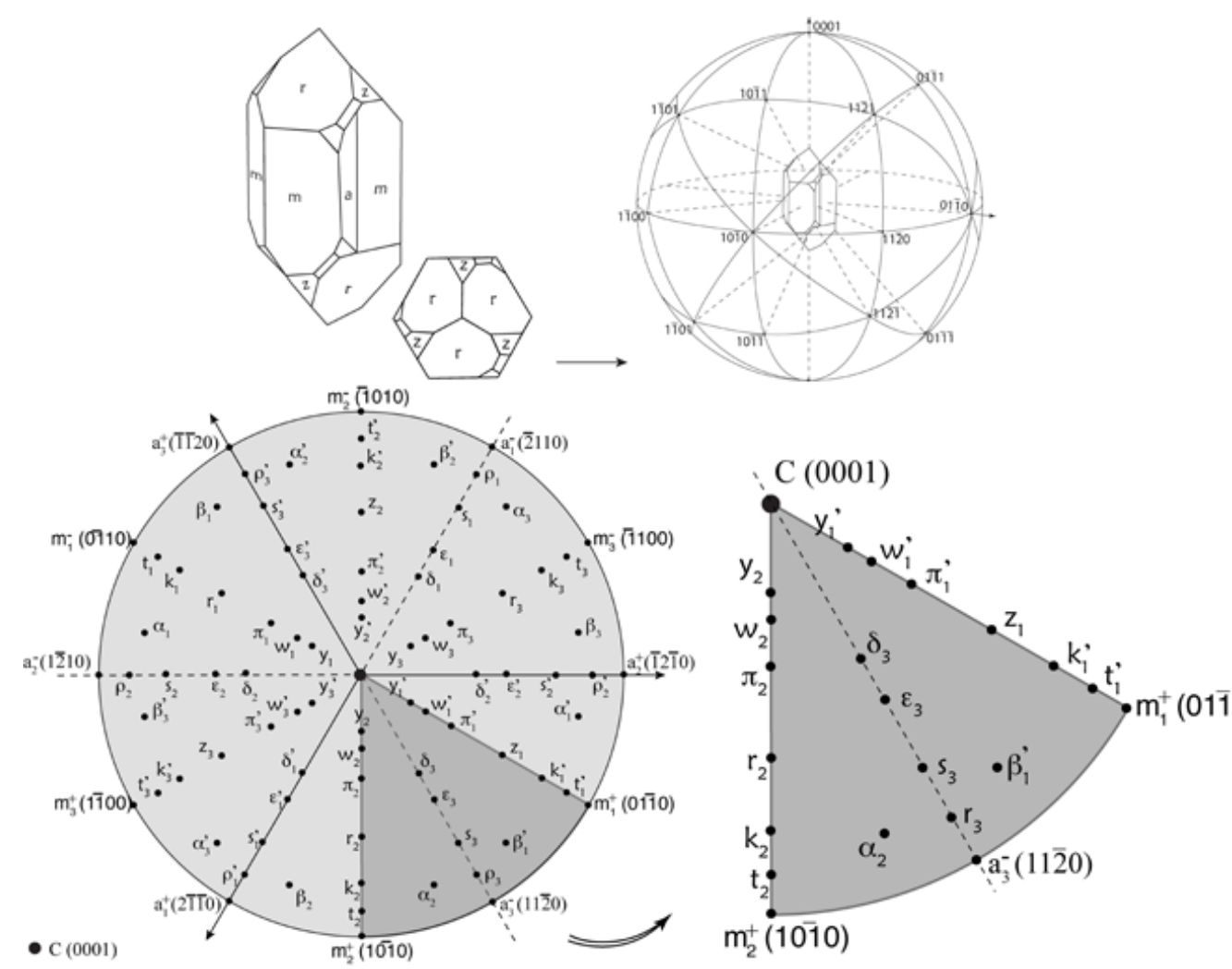

Figure 12 - Main crystallographic forms to quartz grain, in detail the sector used to analyze the distribution of rock structures according to main crystallographic forms to quartz grains - inverse pole figures (after Linker \& Kirby 1984, Nesse 2000, Lloyd 2004).

orientations (Humphreys 2001). The pair angle/axis of misorientation is used (Fig. 13).

According to Wheeler et al. (2001) and Lloyd (2004) the misorientation patterns should be analyzed as a microstructural parameter dependent on crystallography. The misorientation angles are represented as frequency histograms while the misorientation axes distribution should be evaluated according to sample reference system (pole figures) and crystal reference systems (inverse pole figures).

The distribution pattern of angle/axis misorientation pair is common to any quartz aggregate (Wheeler et al. 2001). What should vary in samples with different grain boundaries configurations or samples submitted to different deformational processes is the concentration of misorientation axis around determined crystallographic orientation. Therefore, the misorientation information is used to put some constrain on the deformation mechanism at grain scale. Physically and trigonometrically, these data represent the surface shared by two contiguous grains (Fig. 13) and then the pair axis/ angle of misorientation should be enough to characterize, statistically, the grain boundary geometry (Randle 1992), although the grain boundaries orientations can be inferred from these data but not directly measured.

METHOD RESTRICTION The main restriction of EBSD is that it is not possible to measure the orien- tation of grain boundary yet. Therefore the use of Ustage is necessary for a complete data acquisition of grain boundary configuration. Although through EBSD technique is possible to analyze hundreds of grains in few hours, this technique only allows a statistic treatment of the data, which is not sufficient to determine precisely the grain boundary distribution, particularly when the boundary geometry is the aim of the study. Also, through the misorientation analysis, it is not possible yet to generate a map where we can determine, to each grain boundary, its relative crystallographic orientation to the both grains limited for it, something that can be done with the u-stage.

When the EBSD technique is used, although the data acquisition is punctual, their treatment is global. Therefore, there is not a direct control between grain boundary morphology and its crystallographic orientation, the mesotexture of the aggregate (Randle 1992). Besides, it is necessary to mention the procedures to sample preparation, once the surface of the analyzed samples through EBSD technique must be free of any irregularity. To attend this exigency the sample must be carefully prepared, increasing the costs of the procedure and the time required in the initial steps of the work.

U-STAGE AND EBSD AS COMPLEMENTARY TECHNIQUES When optical microscopy is used, through mosaics of photomicrographs, a segmented im- 


\begin{tabular}{|c|c|c|c|c|c|}
\hline$\underline{\text { Svmbols }}$ & $\frac{\text { Miller-Bravais }}{\underline{\underline{\text { Indices }}}}$ & Angle * & $\underline{\text { Svmbols }}$ & $\frac{\text { Miller-Bravais }}{\underline{\text { Indices }}}$ & Angle* \\
\hline$t_{1}^{\prime}$ & $04 \overline{4} 1$ & $79^{\circ}$ & $\mathrm{k}_{2}$ & 2021 & $69^{\circ}$ \\
\hline $\mathbf{k}_{1}^{\prime}$ & 0221 & $69^{\circ}$ & $\mathrm{r}_{2}$ & $10 \overline{11}$ & $52^{\circ}$ \\
\hline$\pi_{1}^{\prime}$ & 0112 & $33^{\circ}$ & $\mathrm{Z}_{2}$ & $\overline{1} 011$ & $52^{\circ}$ \\
\hline$\omega_{1}^{\prime}$ & 0113 & $23^{\circ}$ & $\pi_{2}$ & 1012 & $33^{\circ}$ \\
\hline$\Psi_{1}^{\prime}$ & 0114 & $18^{\circ}$ & $\omega_{2}$ & 1013 & $23^{\circ}$ \\
\hline$\delta_{1}^{\prime}$ & $2 \pi 13$ & $42^{\circ}$ & $\Psi_{2}$ & $10 \overline{14}$ & $18^{\circ}$ \\
\hline$\varepsilon_{1}^{\prime}$ & 2112 & $48^{\circ}$ & $\delta_{2}$ & $1 \overline{2} 13$ & $42^{\circ}$ \\
\hline $\mathbf{s}_{1}^{\prime}$ & 2111 & $66^{\circ}$ & $\varepsilon_{2}$ & $1 \overline{2} 12$ & $48^{\circ}$ \\
\hline$\rho_{1}^{\prime}$ & 4221 & $77^{\circ}$ & $\mathrm{S}_{2}$ & 1211 & $66^{\circ}$ \\
\hline$\alpha_{1}^{\prime}$ & $\overline{1} 3 \overline{21}$ & $74^{\circ}$ & $\rho_{2}$ & 2421 & $77^{\circ}$ \\
\hline$\beta_{1}^{\prime}$ & $12 \overline{31}$ & $74^{\circ}$ & $\alpha_{2}$ & $21 \overline{3} 1$ & $74^{\circ}$ \\
\hline$\Psi_{1}$ & 0114 & $18^{\circ}$ & $\beta_{2}$ & 3121 & $74^{\circ}$ \\
\hline$\omega_{1}$ & 0113 & $23^{\circ}$ & $\mathrm{t}_{3}^{\prime}$ & 4401 & $79^{\circ}$ \\
\hline$\pi_{1}$ & 0112 & $33^{\circ}$ & $\mathrm{k}_{3}^{\prime}$ & $2 \overline{2} 01$ & $69^{\circ}$ \\
\hline$r_{1}$ & $0 \overline{1} 11$ & $52^{\circ}$ & $\pi_{3}^{\prime}$ & 1102 & $33^{\circ}$ \\
\hline$z_{1}$ & $01 \overline{11}$ & $52^{\circ}$ & $\omega_{3}^{\prime}$ & 1103 & $23^{\circ}$ \\
\hline $\mathrm{k}_{\mathrm{l}}$ & $0 \overline{2} 21$ & $69^{\circ}$ & $\Psi_{3}^{\prime}$ & 1104 & $18^{\circ}$ \\
\hline$t_{1}$ & $0 \overline{4} 41$ & $79^{\circ}$ & $\delta_{3}^{\prime}$ & 1123 & $42^{\circ}$ \\
\hline$\rho_{1}$ & $\overline{4} 221$ & $77^{\circ}$ & $\varepsilon_{3}^{\prime}$ & $\overline{11} 22$ & $48^{\circ}$ \\
\hline $\mathrm{S}_{1}$ & $\overline{2} 111$ & $66^{\circ}$ & $S_{3}^{\prime}$ & 1121 & $66^{\circ}$ \\
\hline$\varepsilon_{1}$ & $\overline{2}_{1112}$ & $48^{\circ}$ & $\rho_{3}^{\prime}$ & 2241 & $77^{\circ}$ \\
\hline$\delta_{1}$ & $\overline{2} 113$ & $42^{\circ}$ & $\alpha_{3}^{\prime}$ & 3211 & $74^{\circ}$ \\
\hline$\alpha_{4}$ & 1321 & $74^{\circ}$ & $\beta_{3}^{\prime}$ & $2 \overline{3} 11$ & $74^{\circ}$ \\
\hline$\beta_{1}$ & $\overline{1231}$ & $74^{\circ}$ & $\Psi_{3}$ & $\overline{1104}$ & $18^{\circ}$ \\
\hline $\mathrm{t}_{2}^{\prime}$ & $\overline{4} \mathbf{4 0 4 1}$ & $79^{\circ}$ & $\omega_{3}$ & $\bar{i} 1103$ & $23^{\circ}$ \\
\hline $\mathrm{k}_{2}^{\prime}$ & $\overline{2} 021$ & $69^{\circ}$ & $\pi_{3}$ & $\overline{1} 1102$ & $33^{\circ}$ \\
\hline$\pi_{2}^{\prime}$ & 1012 & $33^{\circ}$ & $r_{3}$ & 1101 & $52^{\circ}$ \\
\hline$\omega_{2}^{\prime}$ & 1013 & $23^{\circ}$ & $\mathrm{Z}_{3}$ & 1101 & $52^{\circ}$ \\
\hline$\Psi_{2}^{\prime}$ & 1014 & $18^{\circ}$ & $\mathrm{k}_{3}$ & 2201 & $69^{\circ}$ \\
\hline$\delta_{2}^{\prime}$ & $\overline{1213}$ & $42^{\circ}$ & $t_{3}$ & $\overline{4} 401$ & $79^{\circ}$ \\
\hline$\varepsilon_{2}^{\prime}$ & 1212 & $48^{\circ}$ & $\rho_{3}$ & $22 \overline{4} 1$ & $77^{\circ}$ \\
\hline$s_{2}^{\prime}$ & $\overline{1211}$ & $66^{\circ}$ & $\mathrm{S}_{3}$ & $11 \overline{21}$ & $66^{\circ}$ \\
\hline$\rho_{2}^{\prime}$ & $\overline{2421}$ & $77^{\circ}$ & $\varepsilon_{3}$ & $11 \overline{22}$ & $48^{\circ}$ \\
\hline$\alpha_{2}^{\prime}$ & $\overline{21} 31$ & $74^{\circ}$ & $\delta_{3}$ & $11 \overline{23}$ & $42^{\circ}$ \\
\hline$\beta_{2}^{\prime}$ & $\overline{3} 121$ & $74^{\circ}$ & $\alpha_{3}$ & 3211 & $74^{\circ}$ \\
\hline $\mathrm{t}_{2}$ & $40 \overline{41}$ & $79^{\circ}$ & $\beta_{3}$ & $\overline{2} 311$ & $74^{\circ}$ \\
\hline
\end{tabular}

Table 1 - The crystallographic forms showed in figure 12 (*angles between the pole of crystallographic form and the c-axis) (Nicolas \& Poirier 1976, Linker \& Kirby 1984, Nesse 2000, Lloyd 2004).

age is generated based on the grain boundaries, which allows that grain size distributions, the axial ratios and shape-preferred orientation are analyzed. On the other hand, using the U-stage, it is possible to measure the distribution patterns of crystallographic orientations of the grains and their boundaries, data presented through pole figures (stereograms) and rosettes. As all grains whose boundaries planes and c-axis were measured are indexed, as well as their boundaries segments (Fig. 7), their orientations can be analyzed individually or establishing relations between them. The length of grain boundary segments and the angular relation between the measured parameters (grain boundary pole and c-axis) are represented in frequency histograms, which allows the separation of grain populations with similar characteristics, such as microstructures, crystallographic orientations and grain boundary configuration. This is the main advantage of the U-stage use, once through the angle between the grain boundary pole and the c-axis of

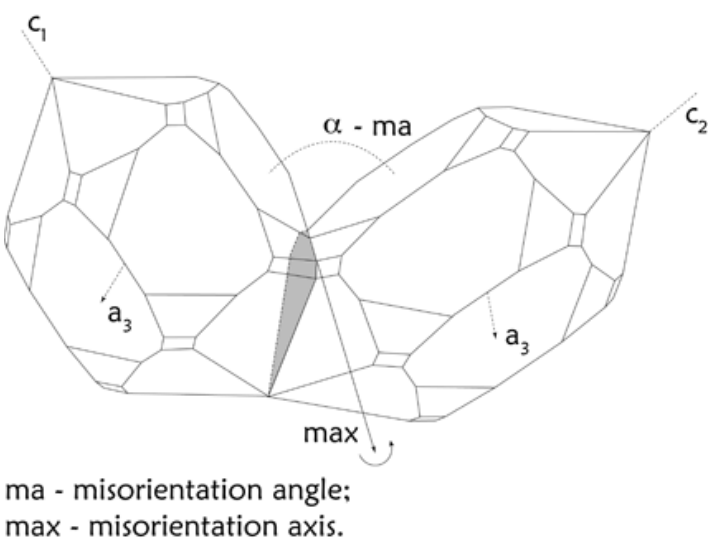

Figure 13 - A pair of neighbor quartz grains where the misorientation axis and the misorientation angle are depicted.

the grain limited for this boundary, the crystallographic plane represented for that boundary can be directly determined. However the EBSD can provide the complete orientation of a crystal, while in the u-stage only the optical axis orientation can be measured or, in some special circumstances, the a-axis orientation (Rosin et al. 2004). Hence, the combined use of both techniques allows the determination of grain boundary orientation, its crystallographic relation with both grains limited by it and the characterization of slip systems active during the deformational processes (Wheeler et al. 2001, Kruhl \& Peternell 2002, Lloyd 2004, Kuntcheva et al. 2006). In the figure 14, there is a convention that can be adopted to determine the crystallographic orientation of grain boundary plane from u-stage data. The sector showed in the figure 12 was divided in sub-sectors according to intervals of angles used to analyze the obtained data in the u-stage, based on the angular relation between the pole of crystallographic plane and $c$-axis.

Then, all crystallographic forms in sub-sector II and III are considered rhombohedral forms, although Nicolas \& Poirier (1976) consider as sub-basal forms, those surfaces with angular relation up to $30^{\circ}$; poles in sub-sector IV are considered trapezohedral forms and those in sub-sector V are prismatic forms. As the presented sector is used to analyze the distribution pattern of any linear structure in the mineral aggregate according crystal reference system, is important to correlate it with the angular intervals used to treat the data obtained via u-stage, so that the results achieved with the u-stage and EBSD can be correlated.

Therefore, although the orientation of all crystallographic planes can be measured, with the EBSD, the orientation of the grain boundary plane cannot be obtained directly and individually. Then, in this case, it is necessary to analyze the misorientation relation between the grains. Thus, the pair angle/axis misorientation should be measured and analyzed, because their distribution pattern jointly with the distribution patterns of crystallographic forms allow the determination of activated slip system and, consequently, the interpretation 


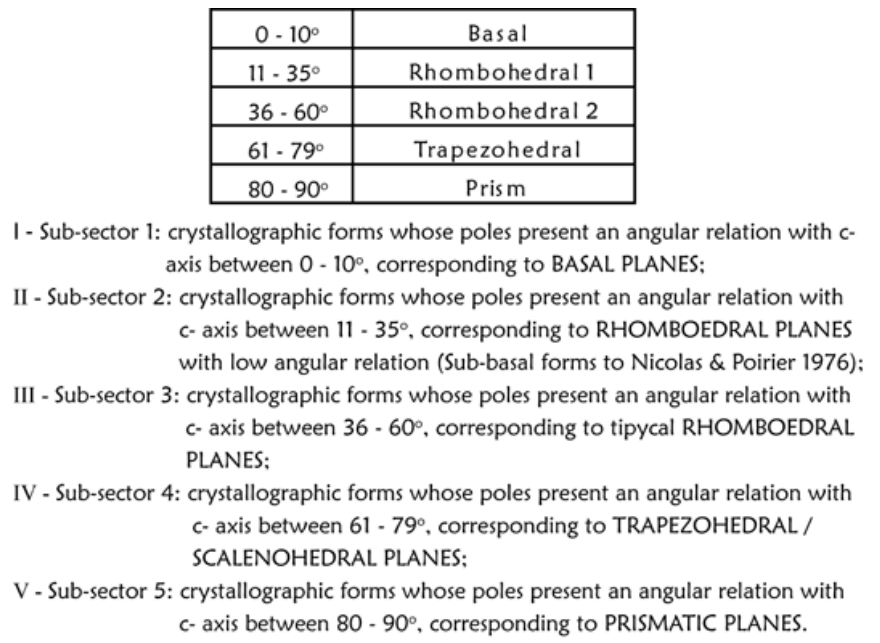

\begin{tabular}{|c|c|}
\hline $0-10^{\circ}$ & Basal \\
\hline $11-35^{\circ}$ & Rhombohedral 1 \\
\hline $36 \cdot 60^{\circ}$ & Rhombohedral 2 \\
\hline $61 \cdot 79^{\circ}$ & Trapezohedral \\
\hline $80-90^{\circ}$ & Prism \\
\hline
\end{tabular}

crystallographic forms whose poles present an angular relation with c-

axis between $11-35^{\circ}$, corresponding to RHOMBOEDRAL PLANES with low angular relation (Sub-basal forms to Nicolas \& Poirier 1976); c- axis between $36-60^{\circ}$, corresponding to tipycal RHOMBOEDRAL PLANES; c- axis between $61-79^{\circ}$, corresponding to TRAPEZOHEDRAL/

c- axis between $80-90^{\circ}$, corresponding to PRISMATIC PLANES.

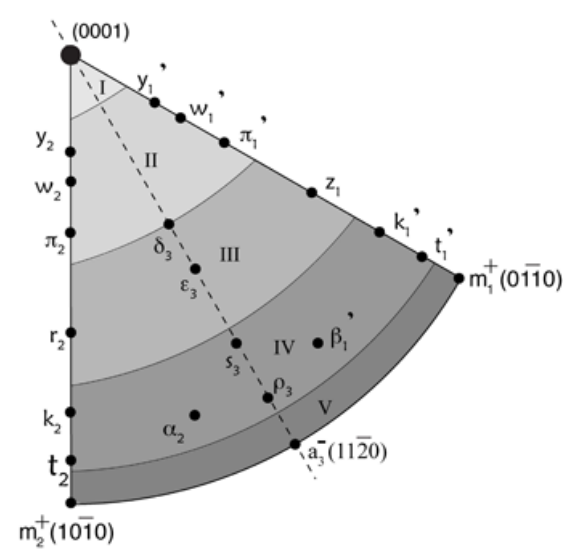

Figure 14 - Angular intervals used to determine the crystallographic orientation of grain boundary. (crystallographic forms are described in figure 13).

of grain boundary orientation (considering plastically deformed aggregates, Lloyd 2004).

Even that the integration of all those data obtained via EBSD allows a complete analysis of the relationships between crystal lattices, grain boundary orientations are treated indirectly, because the interfacial boundary cannot be measured in the EBSD. Grain boundaries are mapped out automatically in the EBSD, but the equipment cannot resolve spatially the orientation of grain boundary once they are interpolated between two neighboring phases with pre-determined orientation contrast $\left(>10^{\circ}\right.$, for example). Therefore, to overcome this limitation of the EBSD technique the Ustage should be used, since it allows the spatial control of orientations of grain boundary interfaces and then, these techniques should be treated as complementary and not as substitutive methods.

\footnotetext{
AN EXAMPLE OF GRAIN BOUNDARY PATTERNCHARACTERIZATION Quartzaggregates, which came from banded iron formation of Quadrilátero Ferrífero region, were analyzed, considering the metamorphic gradient from west to eastern areas of the region that has been characterized for researchers (Pires 1995, Rosière 2001). The data relative to microstructural features are presented through mosaics, frequency histograms and rosettes (Fig. 15). Taking into account the quartz aggregates from different metamorphic and deformational contexts, the aim is to compare the grain size distribution (Fig. $15 \mathrm{~b}, \mathrm{I}-\mathrm{II}$ ), the axial ratio of the grains (Fig. 15 c, I-II), as well as their shape-preferred orientation (Fig. $15 \mathrm{~d}, \mathrm{I}-\mathrm{II}$ ) and associate these data with the grain boundary geometry and its orientation pattern (Castro 2007, Castro \& Lagoeiro 2008). Through the presented data, it is clear that the grains become larger and the axial ratio decreases from lowest temperature condition to higher temperature levels. As for the analysis of grain boundary microstructures it is necessary to combine the U-stage and EBSD data these data will be treated separately.
}

The distribution patterns of crystallographic orientation must also reflect the increase in the metamorphic conditions. Then, the preferred orientations must become stronger from lower to higher temperature levels and the crystal plastic processes responsible for the recrystallization of the aggregates must reflect the regional deformational conditions. These data, obtained mainly via EBSD once only c-axes distribution patterns can be easily determined using U-stage, are presented in the figure 16, as pole figures. It is clear that the caxes distribution pattern become more concentrated for the higher metamorphic conditions and it indicates that the metamorphism increases once a Type II crossed girdle become an asymmetrical single girdle for the higher temperature levels (Schmid \& Casey 1986) (Fig. 16 a, I-II). The distribution patterns identified for the poles of prismatic planes are in agreement with the metamorphic gradient (Fig. 16 b, I-II). In the lower temperature conditions, the poles are distributed according to wide girdle, with broad spreading, but the maximum concentration is close to stretching lineation (Fig. 16 b, I). This textural pattern is compatible with the activation of slip system according to basal planes, what is in agreement with the c-axes distribution pattern, whose maxima concentration forms high angle with the rock foliation (Fig. 16 a, I). This is a typical crystal plastic process in low metamorphic condition (Schmid \& Casey 1986, Law et al. 1990, Law 1990, Hirth \& Tullis 1992, Stipp et al. 2002). In the higher metamorphic condition the preferred orientations become stronger once the girdle generated for the poles of prisms is better defined (Fig. 16 b, II). The orientation patterns of poles of rhombohedral planes, although show a wide dispersion, become stronger in the domain with higher temperature condition, in agreement with the further textural data (Fig. $16 \mathrm{c}, \mathrm{I}-\mathrm{II}$ ).

Besides pole figures, orientation contrast images and orientation contrast maps can be generate, which can illustrate the preferred orientation of the grains (Fig. 17 a-b). It's necessary to consider that in the orientation contrast image, or forescattering image, the differences 
a) I)

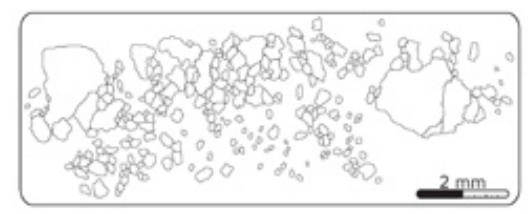

b) (1)

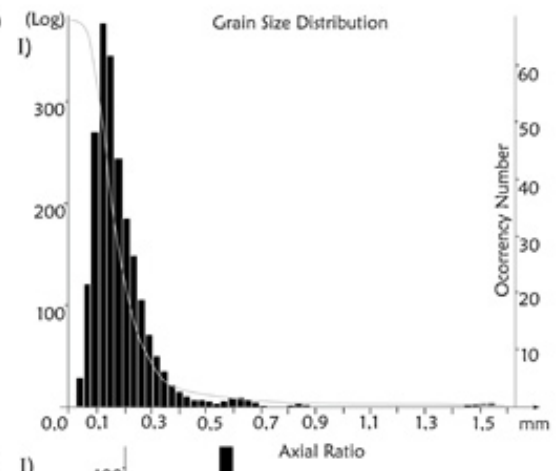

c) 1)

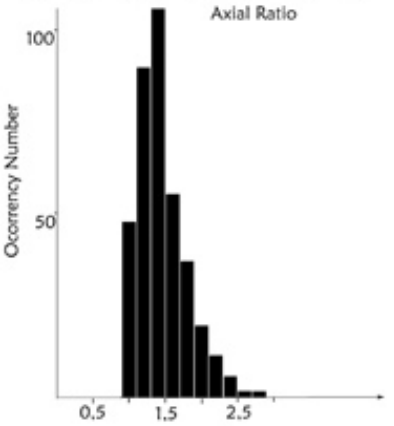

d) 1)

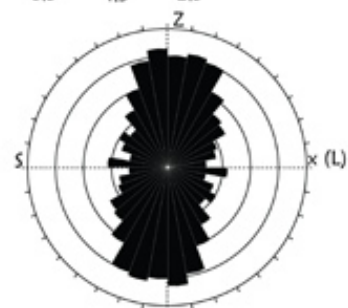

II)

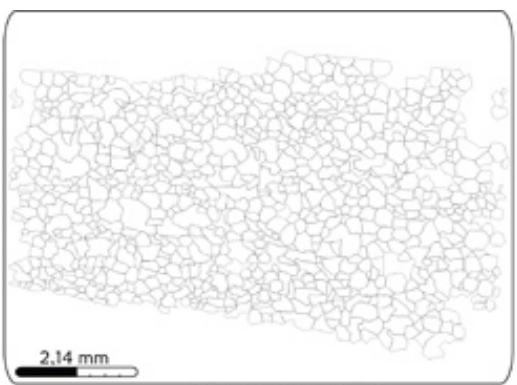

II)

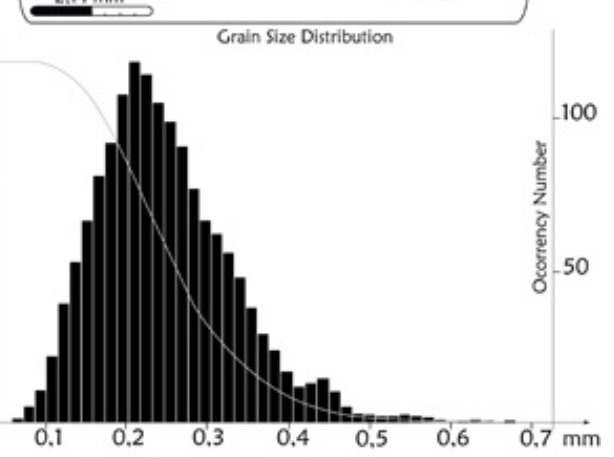

II)

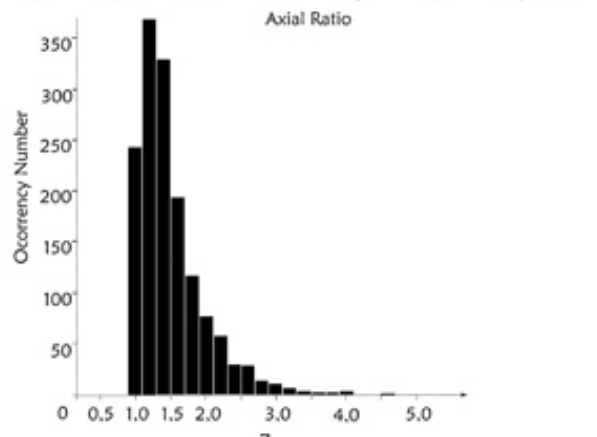

II)

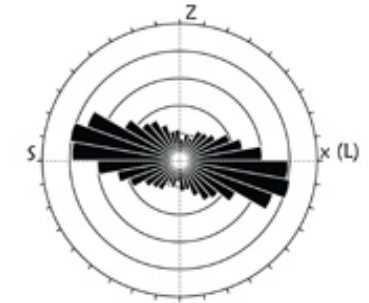

Figure 15 - Quantifying Microstructures; a) segmented images generated on mosaics of quartz bands, from which grain size distribution (b), axial ratio (c) and grain shape preferred orientation (d) were determined; I) lower metamorphic condition; II) higher metamorphic condition.

in gray scale represents different crystallographic orientations, but the color intensity is not directly related with the angular misfit. Other factors interfere in the gray scale, for example, the depth reached for the electron beam in the sample. However, for the orientation contrast map, the colors are directly related with the angular difference among the grains. In addition to the mentioned data, the rock structures can be plotted according to crystal reference system, as inverse pole figures. Then, it is possible to analyze according to what crystallographic direction a rock structure, lineation or foliation pole, for example, is oriented. In this case, the mineral lineation is preferentially oriented according to poles of trapezohedral planes for lower metamorphic conditions and rhombohedral planes for the higher levels, although wide spreading is observed (Fig. $17 \mathrm{c}-\mathrm{d}$ ).

To determine the five parameters required for the grain boundaries arrangement characterization we have used the U-stage and EBSD simultaneously. Two of the five parameters are determined when the geometry and orientation patterns of boundary surfaces are characterized, using the U-stage. Considering the straight grain boundary segments the orientations of their correspondent grain boundary surfaces are determined and then the orientation patterns of boundary poles and rosettes showing the orientation of grain boundary segments are analyzed (Fig. 18 a-b, I-II). Besides, the length of grain boundary segments are measured and plotted as histograms (Fig. 18 a-b, III). Based on the figure 18, it is clear that in the higher metamorphic condition, the grain boundary become larger (Fig. 18 a-b, III) and boundaries at high angle with the rock foliation appear, while in the lower temperature conditions those boundaries parallel to the rock foliation predominate widely (Fig. 

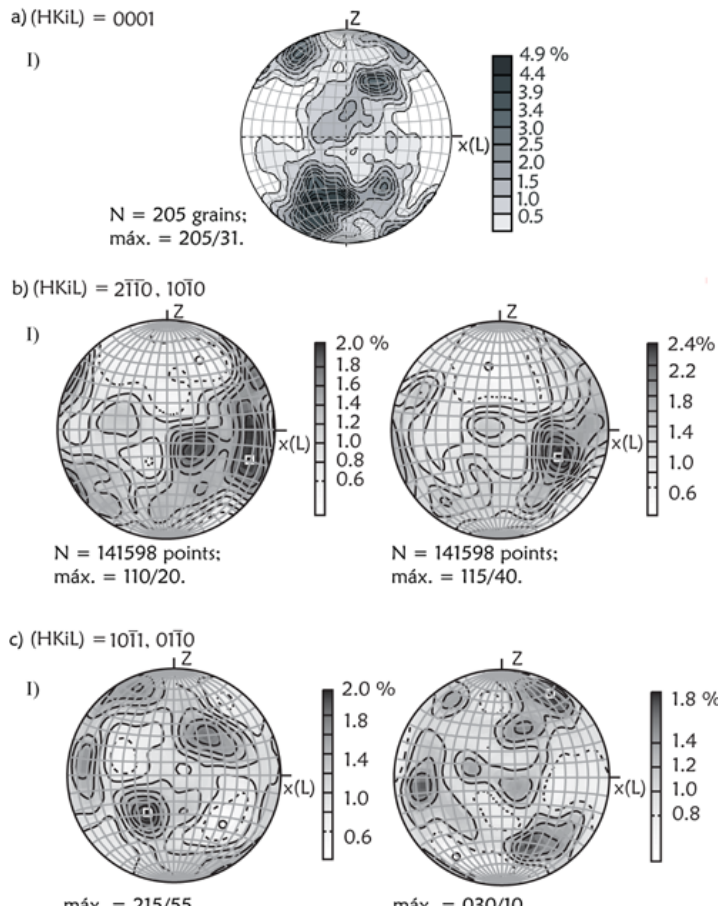

Numbers of points is the same in letter $b$.

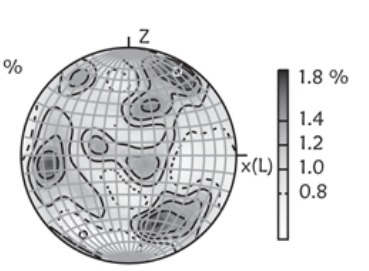

máx. $=030 / 10$
II)

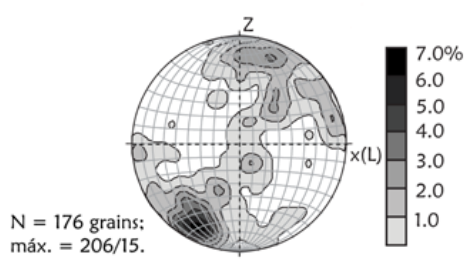

II)

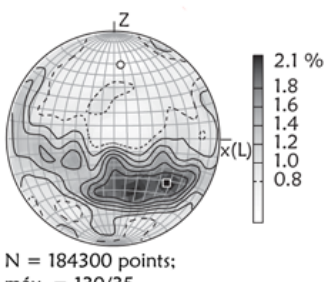

máx. $=130 / 35$.

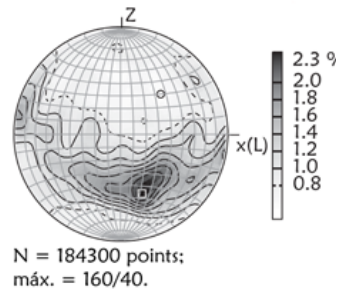

II)
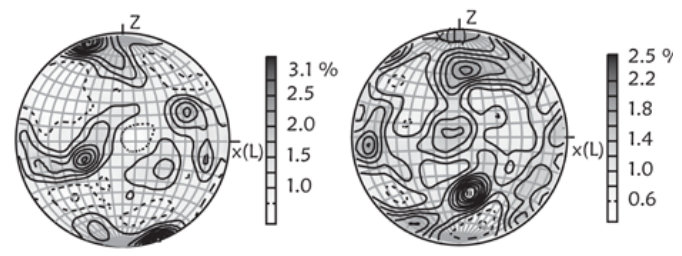

máx. $=170 / 45$.

Figure 16 - Crystallographic orientation patterns, according to sample reference system: $x(L)$-stretching lineation; $Z$-foliation pole; a) orientation patterns of c-axes; $b$ ) orientation patterns of poles of prisms; c) orientation patterns of poles of rhombs; I) lower metamorphic conditions; II) higher metamorphic conditions.
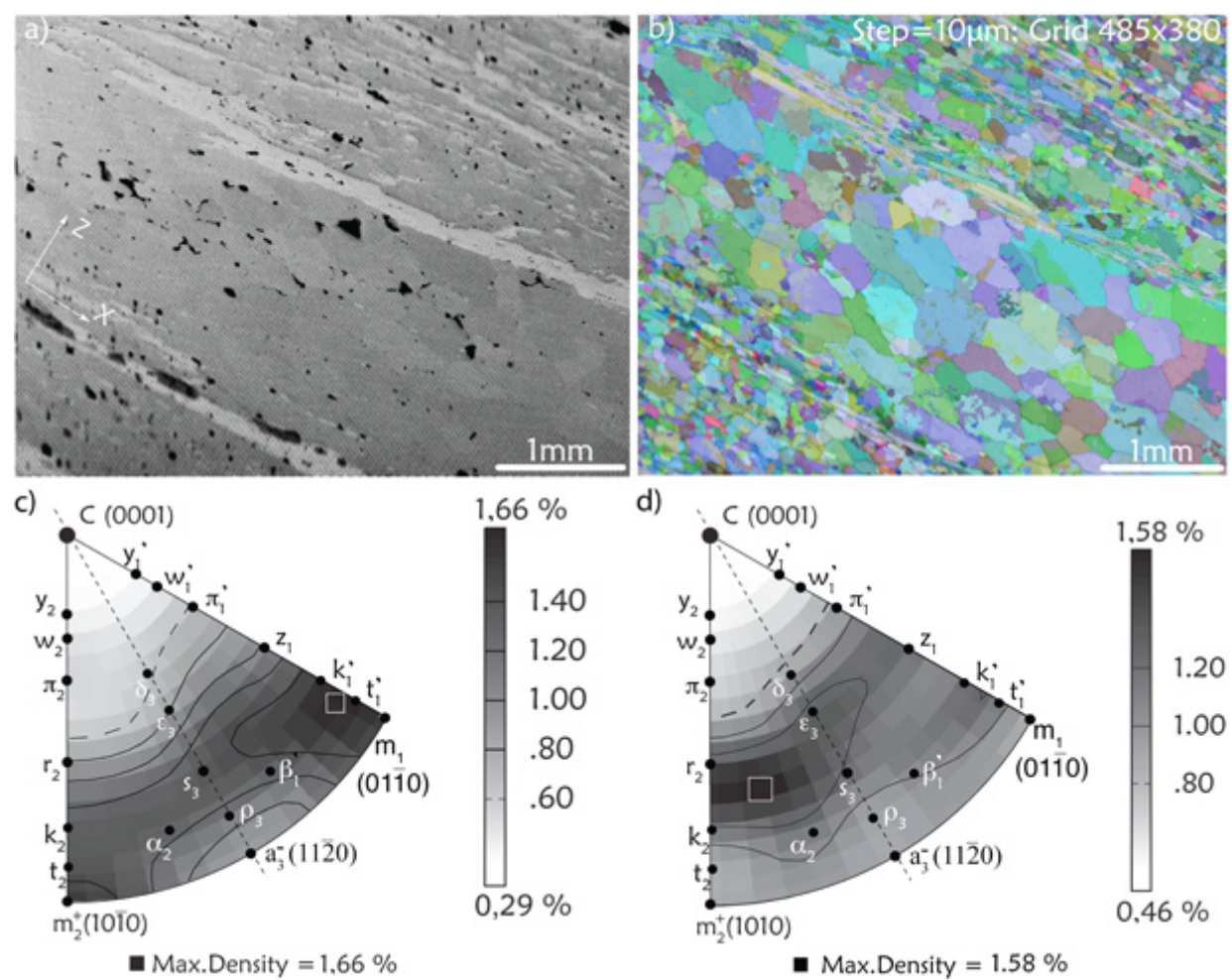

Figure 17 - a) orientation contrast image of forescattering electrons (light gray, hematite plates parallel to $x$ direction, and dark gray, polygonal quartz crystals); b) orientation contrast map, after data refinement (zero solution $=$ $2 \%) ; c-d)$ inverse pole figure showing the orientation pattern of stretching lineation ( $x$ direction) according to crystal forms, for lower and higher metamorphic conditions, respectively ( $N=77746$, lower hemisphere). 

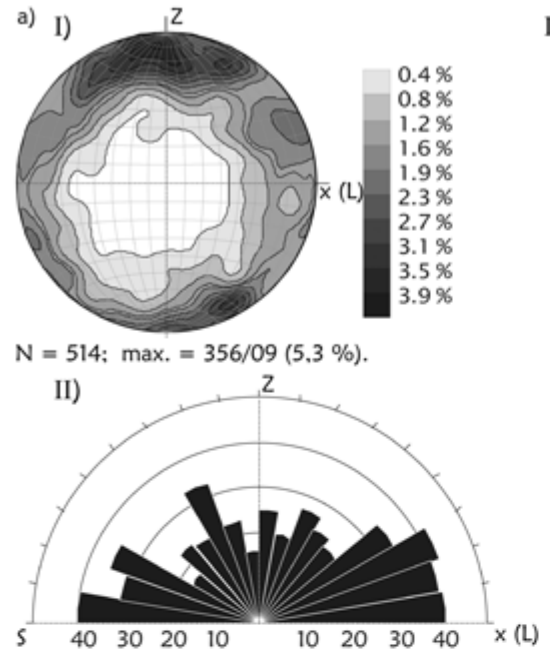

b) I)

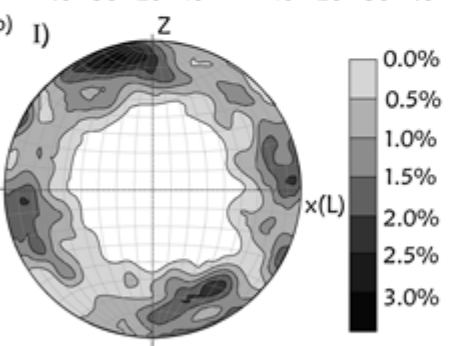

$\mathrm{N}=492: \max .=344 / 10(3.8 \%)$.

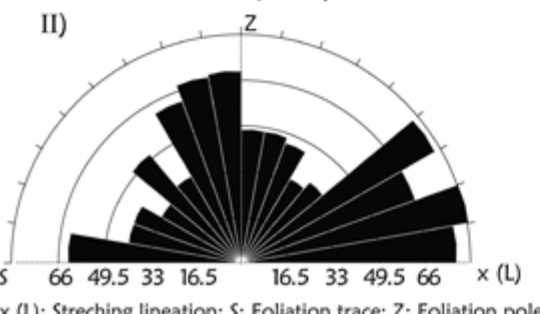

III)

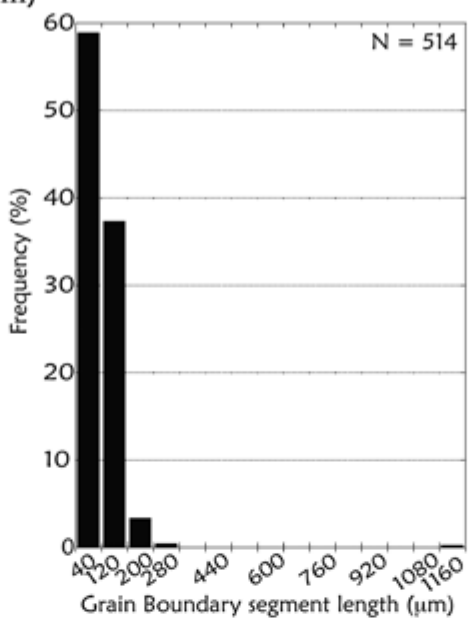

III)

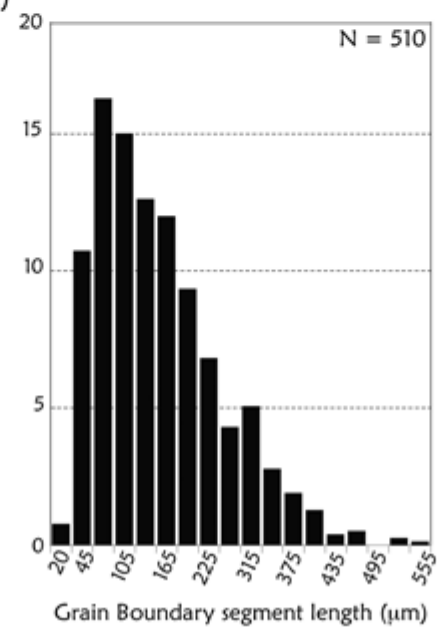

IV)

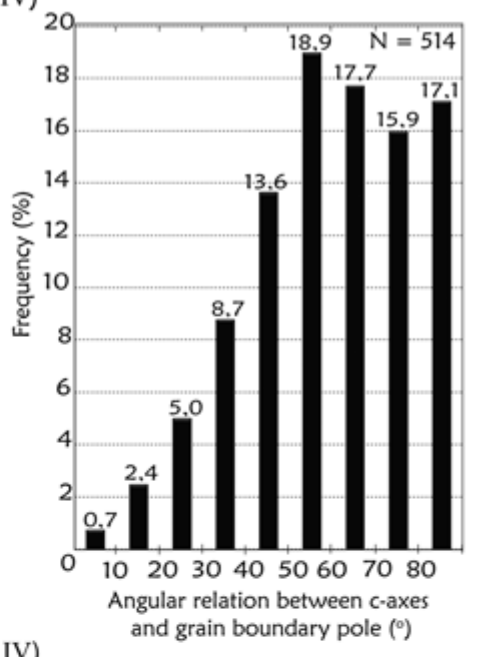

IV)

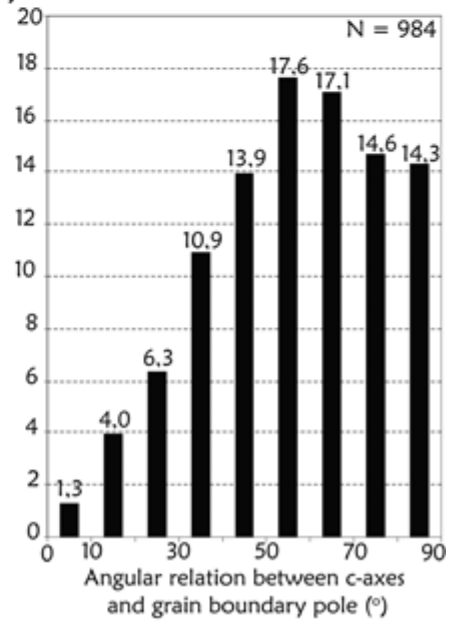

Figure 18 - Grain boundary orientation from U-stage; I) pole figures showing the orientation distribution pattern of grain boundary poles; II) orientation of straight line segments of grain boundaries; III) Length distribution of straight grain boundary segments; IV) c-axis and grain boundary pole angles. a) lower metamorphic conditions and b) higher metamorphic condition.

$18 \mathrm{a}-\mathrm{b}, \mathrm{I}-\mathrm{II})$. Moreover, if the c-axes distribution pattern is considered (Fig. 16 a-b, I) the grain boundaries orientations evince the preferential occurrence of boundaries at high angle with the c-axes in the low metamorphic condition and the arising of boundaries forming lower angles with the c-axes in the higher temperature levels. This configuration becomes clearer when the angles between the c-axes and grain boundary poles are analyzed (Fig. 18 a-b, IV).

The histograms in the figure 18 (a-b, IV) show that, virtually, the poles of grain boundaries can present any angular relation with the c-axes. This orientation pattern indicates grain boundary planes oriented according to any crystallographic form. However, when the grain boundary plane orientation is analyzed for each grain delimited for it, such boundary represents preferentially a rhomb plane to one grain and a trapezohedral to its neighbor (Fig. 19). Besides, as the grain boundary segments lengths are measured it is possible to analyze the grain boundary orientation to different intervals of their lengths, what is represented in the figure 19. Comparing the histograms, we observe that a boundary never represents a basal plane for both grains that share it. Moreover, those boundaries, which represent rhombohedral (Rhomb2 - Fig. 14) and trapezohedral planes, become larger in detriment of those oriented according to basal and Rhomb 1 (Fig. 14) planes. In the higher metamorphic domain, where the larger boundaries measured occur, there is a tendency to the boundary represent the same crystallographic plane for the grains that share it (Fig. 19 - IV), what can indicate the occurrence of twin surfaces between the lattices.

Two of the five parameters required to grain boundary characterization were determined, but the other three are related with the misorientation among the grains, obtained by EBSD technique. The misorientation angles should be analyzed for neighbor and random grains once the difference in their distribution indicates the correlation between neighbor grains due to recrystallization, nucleation, growth twinning or me- 

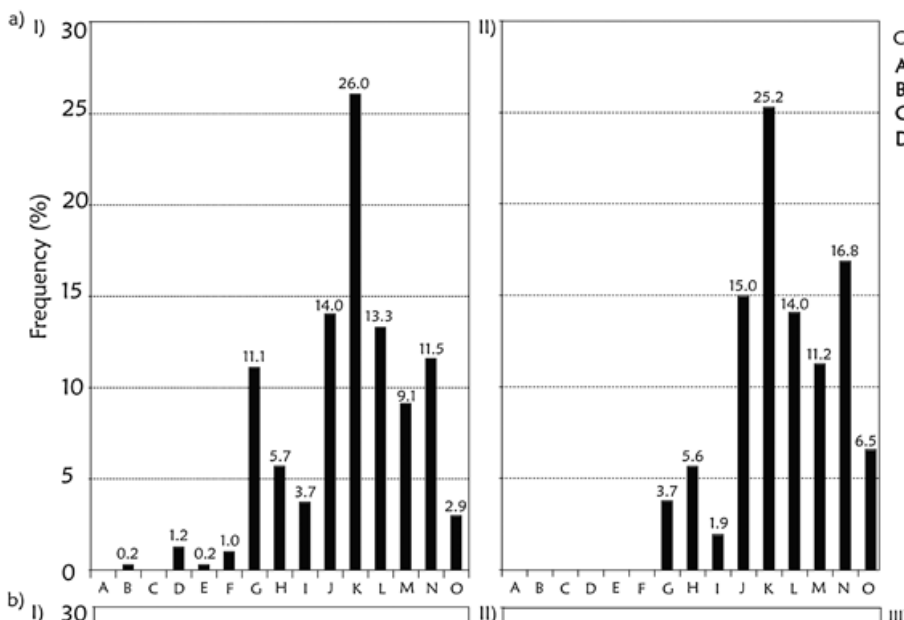

Combinations of crystallographic orientation, if both grains that share a boundary are considered: A - Basal - Basal: $\quad$ E- Basal - Prisma: $\quad 1$ - Rombl - Prisma: M-Trap. - Trap.: B - Basal-Romb1: F-Romb1-Romb1: J-Romb2 - Romb2; N-Trap. - Prisma: C - Basal - Romb2; G- Romb1 - Romb2: K - Romb2 - Trap.: O- Prisma - Prisma. D - Basal-Trap.; $\quad$ H-Rombl - Trap.; $\quad$ L-Romb2 - Prisma:

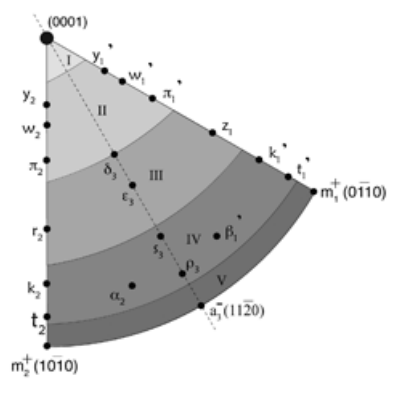

Crystal Reference System represented through a sector of $60^{\circ}$ and the sub-sectors adopted to determined the crystalographic orientation of Grain Boundary.
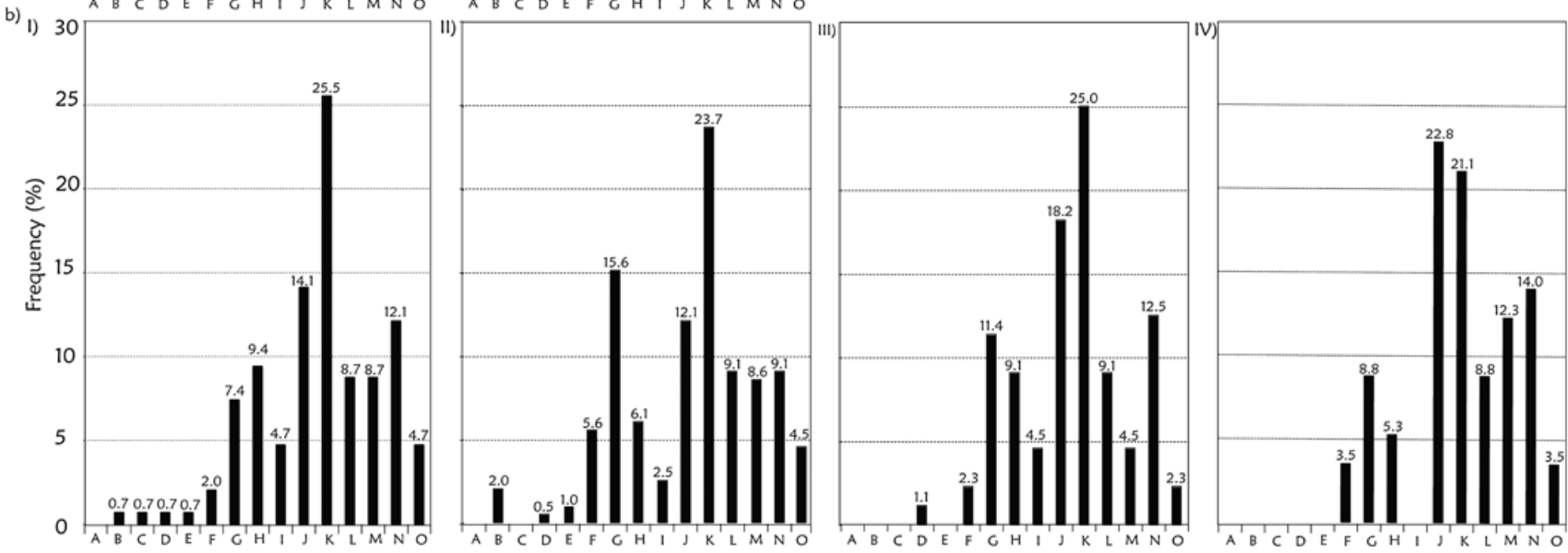

Figure 19 - Distribution of interfacial Crystallographic planes for neighbor pair or boundaries shared by pairs of neighboring grains for the following intervals of straight segment lengths:

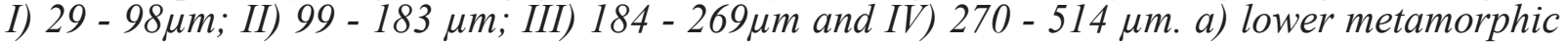
conditions and b) higher metamorphic condition.

chanical twinning (Wheeler et al. 2001). Then, using histograms (Fig. 20 a-b), we observe that the difference in the misorientation angles distribution between neighbor and random grains become stronger in the high metamorphic level. Besides, there is a maxima point at $55-60^{\circ}$, being that for this angles the misorientation axes are parallel to the c-axes (inverse pole figures in the figure 20), what correspond to the operation of Dauphiné twin. On the other hand, for angles between 35 and $40^{\circ}$ the misorientation axes can be oriented according to $<\mathrm{a}>$ direction, what is not waited once this must be the main slip direction for the crystallographic patterns observed (Lloyd 2004). This pattern should indicate the occurrence of secondary processes, here interpreted as bulging process (Stipp et al. 2002). As this is a typical process of lower metamorphic condition, the occurrence of misorientation axes orientated according to $<$ a $>$ direction should decrease in the higher temperature levels, what is observed when the inverse pole figures in the figure 20 (a-b) are compared.

CONCLUSIONS The aim of all processes developed during the deformation of mineral aggregates is to recover stabler energy stages and in this sense the grain boundary arrangement is fundamental. The grain bound- ary surfaces represent the adjustment between neighbor lattices and as they should be treated as discontinuities between adjacent crystals, they have a wide influence on the physical, chemical and mechanical properties of mineral aggregates. However, the characterization of grain boundaries geometry and their preferred orientation in different deformational and metamorphic contexts remain poorly understood, due, mainly, to difficulties to determine all parameters required for a complete boundary characterization. In this sense, the methodology presented should become a useful method for grain boundary analysis once a complete boundary characterization is made:

i) Analysis of grain boundary geometry and their orientation, according to sample reference system and crystal reference system; ii) Determination and analysis of misorientation relations: angle/axis misorientation pair; iii) Characterization of those textural parameters for different metamorphic and deformational contexts, what allows to recognize grain boundaries arrangement for different tectometamorphic condition; iv) Association between physical properties of the aggregates and different grain boundaries arrangement; v) Determination of grain boundary arrangements that imply lowest energy levels for the mineral aggregates; 

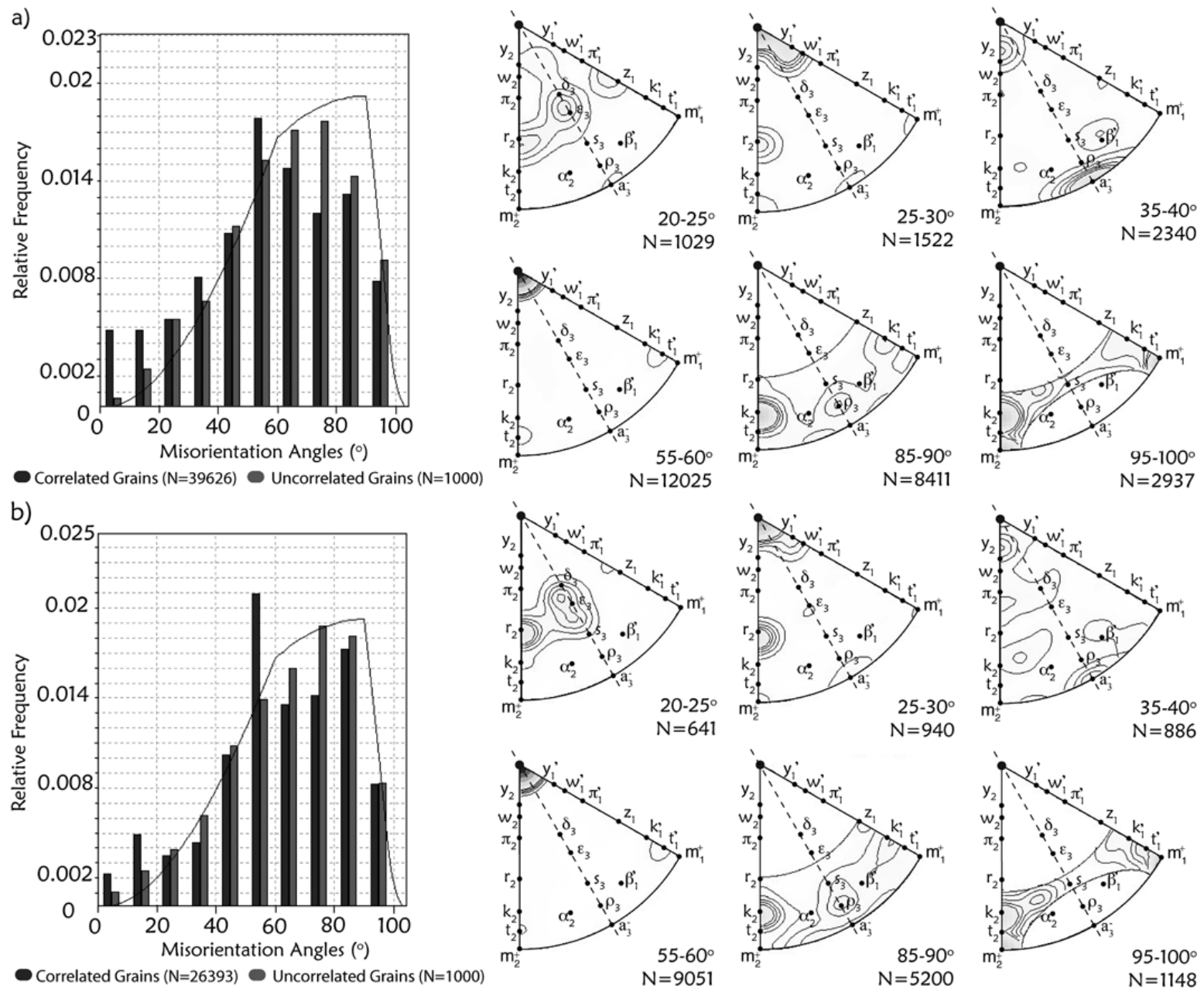

Figure 20 - Misorientation angle distribution and orientation patterns of misorientation axes to some misorientation angles intervals, according to inverse pole figures. a) lower metamorphic conditions and b) higher metamorphic condition.

vi) Characterization of grain boundary geometry and its orientation pattern for aggregates submitted to different recovery processes.

Acknowledgment The authors would like to thank Luiz Fernando Grafulha Morales and Leonardo Eu- stáquio for helpful discussions as well as for the assistance during sample preparation. The financial support by the National Council for research and Technology Development (CNPq) is gratefully acknowledged.

\section{References}

Alkmim F.F. \& Marshak S. 1998. Transamazonian Orogeny in the Southern São Francisco Craton Region Minas Gerais Brazil: evidence for Paleoproterozoic collision and collapse in the Quadrilátero Ferrífero. Precambrian Research, 90:29-58.

Bunge H.J. 1982. Texture Analysis in Materials Science. London: Butterworths. (Reprint: Cuvillier Verlag, Göttingen. 1993).

Castro C.P. 2007. Microestruturas e Textura de Equilibrio em Quartzo Recristalizado. Dissertação de Mestrado, Ufop, 150p.

Castro C.P. \& Lagoeiro L.E. 2008. Grain Boundary Patterns in Dynamically Recrystallized Quartz Aggregates. In: Rollett A. D. Applications of Texture Analysis: Ceramics
Transactions, 201:251-260.

Dingley D.J., Baba-Kishi K.Z., Randle V. 1995. Atlas of Backscattering Kikuchi Diffraction Patterns. Institute of Physics Publishing, Bristol and Philadelphia, 135p.

Fynn G.W. \& Powell W.J.A. 1979. The Cutting and Polishing of Electro-Optic Materials. Adams Hilger, London, 216p.

Heilbronner R. \& Tullis J. 2002. The effect of static annealing on microstructures and crystallographic preferred orientations of quartzites experimentallyy deformed in axial compression and shear. In: de Meer S., Drury M.R., de Bresser J.H.P., Pennock G.M. (eds.) Deformation mechanisms, Rheology and Tectonics: current status and future perspectives. Geological Society of London, 
Special Publication, 200:191-218.

Hippertt J., Lana C., Takesgita T. 2001. Deformation partitioning during folding of banded iron formation. Journal of Structural Geology 23:819-834.

Hirth G. \& Tullis J. 1992. Dislocation creep regimes in quartz aggregates. Journal of Structural Geology, 14:145-159.

Humphreys F. J. 2001. Review - Grain and subgrain characterization by electron backscatter diffraction. Journal of Material Science, 36:3833-3854.

Kruhl J.H. 1996. Prism- and basal-plane glide parallel subgrain boundaries in quartz: a microstructural geothermobatometer. Journal of Metamorphic Geology, 14:581589.

Kruhl J.H. \& Peternell M. 2002. The equilibration of highangle grain boundaries in dynamically recrystallized quartz: the effect of crystallographic and temperature. Journal of Structural geology 24:1125-1137.

Kuntcheva B., Kruhl J.H., Kunze K. 2006. Crystallographic orientations of high-angle grain boundaries in dynamically recrystallized quartz: first results. Tectonophisics 421:331-346.

Lagoeiro L. 1998. Transformation of magnetite to hematite and its influence on the dissolution of iron oxide minerals. Journal of Metamorphic Geology, 16:415-423.

Law R.D. 1990. Crystallographic fabrics: a selective review of their applications to research in structural geology. In: Knipe R.J. \& Rutter E.H. (eds.) Deformation Mechanisms, Rheology and Tectonics. The Geological Society of London Special Publication, p. 335-352.

Law R.D., Schmid S.M., Wheeler J. 1990. Simple shear deformation and crystallographic fabrics: a possible natural example from the Torridon area of NW Scotland. Journal of Structural Geology, 12(1):29-45.

Linker M.F., Kirby S.H. 1984. Effects of compression direction on the plasticity and rheology of hydrolitically weakened synthetic quartz crystals at atmospheric pressure. Journal of Geophysical Research, 89:4241-4255.

Lloyd G. E. \& Freeman B. 1991. SEM electron channeling analysis of dynamic recrystallization in a quartz grain. Journal of Structural Geology, 13(8):945-953.

Lloyd G. E., Farmer A.B., Mainprice D. 1997. Misorientation Analysis and the formation and orientation of subgrains and grain boundaries. Tectonophysics, 279:55-78.

Lloyd G.E. 2004. Microstructural evolution in a mylonitic quartz simple shear zone: the significant roles of dauphine twinning and misorientation. In: Alsop G.I., Holdsworth R.E., McCaffrey K.J.W., Hand M. (eds.) Flow Processes in Faults and Shear zone. Geological Society, London, Special Publication 224:39-61.

Mainprice D. H., Lloyd G. E., Casey M. 1993. Individual orientation measurements in quartz polycrystals - advantages and limitations for texture and petrophysical property determinations. Journal of Structural Geology, 15:1169-1187.

Nesse W.D. 2000. Introduction to Mineralogy. New York, Oxford University Press, 442p.

Nicolas A. \& Poirier J. P. (eds.) 1976. Crystalline Plasticity and Solid State Flow in Metamorphic Rocks. London, John Wiley \& Sons, 444p.

Passchier C.W. \& Trouw R.A.J. (eds.) 1996. Microtectonics. 2nd., Springer Berling, 289p.

Pires F.R.M. 1995. Textural and Mineralogical variations during metamorphism of the proterozoic Itabira iron Formation in the Quadrilátero Ferrífero, Minas Gerais, Brazil. Anais Academia Brasileira de Ciências 67(1):77-105.

Prior D.J., Boyle A.P., Brenker F., Cheadle M.C., Day A., Lopez G., Potts G.J., Reddy S., Spiess R., Timms N., Trimby P., Wheeler J., Zetterstrom L. 1999. The application of electron backscatter diffraction and orientation contrast imaging in the SEM to textural problems in rocks. American Mineralogist, 84:1741-1759.

Prior D.J., Wheeler J., Peruzzo L., Spiess R., Storey C. 2002. Some garnet microstructures: an illustration of the potential of orientation maps and misorientation analysis in microstructural studies. Journal of Structural Geology, 24:999-1011.

Randle V. 1992. Mirostexture determination and its applications. Bourne Press, Great Britain, 174p.

Randle V. \& Engler O. 2000. Introduction to Texture Analysis. Macrotexture, Microtexture \& Orientation Mapping. London, CRC, p. 408.

Rosière C.A., Siemes H., Quade H., Brokmeier H.G., Jansen E.M. 2001. Microstructure, texture and deformation mechanism in hematite. Journal of Structural Geology, 23:1429-1440.

Rosin S. M., Johnson E. L., Mancktelow N. 2004. An optical method for the determination of $<\mathrm{a}>$ axis orientations in deformed aggregates of quartz. Journal of Structural Geology, 26:2059-2064.

Schmid S.M. \& Casey M. 1986. Complete fabric analysis of some commonly observed quartz c-axis patterns. In: Hobbs B.E. \& Heard C. (eds.) Mineral and Rock Deformation: Laboratory Studies - The Paterson Volume. American Geophysical Union, Geophysical Monograph, 36:263-286.

Spry A. 1983. Metamorphic Textures. Inglaterra, Pergamon Press, 352p.

Stipp M., Stünitz H., Heilbronner R., Schmid S.M. 2002. The eastern Tonale fault zone: a 'natural laboratory' for crystal plastic deformation of quartz over a temperature range from 250 to $700^{\circ}$ C. Journal of Structural Geology, 24:1861-1884.

Tullis J., Christie J.M., Griggs D.T. 1973. Microstructures and preferred orientations of experimentally deformed quartzites. Geological Society of America Bulletin, 84:297-314.

Twiss R. J. \& Moores E. M. 1992. Structural Geology. New York, W.H. Freeman and Company, 532p.

Wheeler J., Prior D.J., Jiang Z., Spiess R., Trimby P.W. 2001. The petrological significance of misorientations between grains. Contrib. Mineral Petrology, 141:109-124.

Wheeler J., Jiang Z., Prior D.J., Tullis J., Drury M.R., Trimby P.W. 2003. From Geometry to dynamics of microstructure: using boundary lengths to quantify boundary misorientations and anisotropy. Tectonophysics, 376:19-35.

Manuscrito ID 9841

Submetido em 27 de novembro de 2007 Aceito em 15 de fevereiro de 2009 